\title{
4. EL SISTEMA ELECTORAL \\ DE LA CONSTITUCIÓN DE 1845
}

EUGENIO ULL PONT 
SUMARIO

INTRODUCCIÓN.-LEGISLACIÓN ELECTORAL.-Leyes y proyectos de Ley electoral de 1845 a 1865 . - El proyecto de Ley electoral de Pedro J. Vidal.--Ley electoral de 18 de marzo de 1846.-Gobierno de Bravo Murillo, 1851-1852.-Proyecto de Ley de 1851, sobre disposiciones penales.-Proyecto de Ley electoral de Bravo Murillo.- Nueva vigencia de la Constitución de 1845.El proyecto de elección por insaculación.-Proyecto electoral de la Unión Liberal. - Nuevo proyecto moderado.-Proyecto de Ley electoral de Antonio Benavides.-Ley de 22 de junio de 1864, estableciendo el procedimiento y sanción penal en los delitos electorales. - Ley electoral de 18 de julio de 1865.--Real Decreto de 11 de agosto de 1854.-Normas electorales de la Constitución de 1856.-Proyecto de Ley electoral de Patricio de la Escosura. 


\title{
4. EL SISTEMA ELECTORAL DE LA CONSTITUCIÓN DE 1845
}

POR

\author{
EUGENIO ULL PONT
}

\section{INTRODUCCIÓN}

La Constitución de 1845 se plantea como una reforma de la Constitución anterior por la vía de una Ley ordinaria. Bien es verdad que la Constitución de 1837 no tiene previsto ningún mecanismo especial de reforma.

En realidad significa sentar un precedente partidario en el sistema constitucional, pues en adelante cada partido va a querer tener una Constitución ajustada a su propia horma ideológica.

Pocas modificaciones recibe la Constitución de 1837, pero suficientes para cambiar radicalmente sus contenidos esenciales. La soberanía, conforme a los principios doctrinarios, será atribuida al Rey con las Cortes. Hasta 1869 no se recuperará el principio de soberanía nacional. Las normas electorales se reforman muy significativamente.

Con el Estatuto Real de 1834 se introducía el sufragio censitario indirecto. $Y$ continuando con el principio de sufragio censitario, la Constitución de 1837 establece que el mismo se aplique sin electores interpuestos, es decir, empieza el largo período correspondiente al sistema de sufragio censitario directo. Éste se aplicará con distintas connotaciones que puntualizaremos oportunamente, tanto con la Constitución progresista citada como con la reforma constitucional de los moderados en 1845, hasta 1868, y más tarde con la Restauración, desde 1877 a 1890.

De las normas electorales de la Constitución de 1837 a las correspondientes de la Constitución de 1845 , la diferencia más significativa y 
radical es en lo referente al Senado, que deja de ser electivo. Efectivamente, en la Constitución de 1837, los Senadores, aunque los nombra el Rey, este nombramiento recae necesariamente de entre los miembros de una terna elegida en cada provincia por el mismo cuerpo electoral que elige a los Diputados, y el total de Senadores limitado en número a los tres quintos del número de Diputados. Cada provincia tendría uno como mínimo y el resto se atribuirá proporcional a la población respectiva (arts. 14 y ss. de la Constitución de 1837). Con la Constitución de 1845 desaparece totalmente la base democrática de tales nombramientos al corresponder al Rey su nombramiento, si bien entre determinadas categorías y renta, pero sin refrendo popular alguno. Además, se acentúa una mayor garantía de conservadurismo, al ser nombrados con carácter vitalicio.

Siendo ambos Cuerpos colegisladores constitucionalmente con las mismas facultades (art. 13 en ambas Constituciones), esto significa poner en manos del Gobierno de su Majestad, cuanto menos, la mediatización y bloqueo de aquellos acuerdos del Congreso que no convengan a sus fines.

En la elección de Diputados hay un común denominador de entrada entre ambas Constituciones, al establecer un número mínimo de un Diputado por cada 50.000 habitantes, elección censitaria directa, español seglar, 25 años. También hay una coincidencia que hoy nos llamaría especialmente la atención, el cargo de Senador y el de Diputado es gratuito. La diferencia se marca en la duración del mandato, que pasa de tres a cinco años, y en la circunscripción, que era de carácter provincial y ahora no se define constitucionalmente.

Es la Ley electoral respectiva la que marca las diferencias y a la cual se remite la Constitución para completar los distintos aspectos del proceso electoral. Como veremos, la legislación electoral de la nueva Constitución pondrá condiciones más restrictivas para integrar el Censo electoral, reduciéndole drásticamente en número de electores. También se reducirá la circunscripción, lo cual permitirá un mejor "control» del proceso.

\section{LEGISLACIÓN ELECTORAL}

Las Cortes que realizaron la reforma constitucional fueron elegidas el 3 de septiembre de 1844. La apertura de sus sesiones se celebró el 10 de octubre y se clausuró su primer período parlamentario con la promulgación de la Constitución, el 23 de mayo de 1845. Su segundo período de 
sesiones empezó el 15 de diciembre del mismo año, siendo suspendidas el 17 de marzo de 1846, clausuradas el 30 de octubre y finalmente disueltas el día siguiente.

Las nuevas Cortes, mejor dicho el Congreso, sería elegido el 6 de diciembre de 1846 y su apertura solemne el día de San Silvestre. Rige ya la normativa de la Constitución de 1845 y su Ley electoral de 18 de marzo de 1846.

Pero volvamos al hilo conductor de la reforma constitucional, a partir de la caída de Espartero y la declaración de la mayoría de edad de Isabel II, para evitar tener que nombrar otro regente. Las referidas Cortes de 1844 se componían prácticamente de sólo moderados, en contrapunto con las anteriores. La elección de las mismas se realizó de acuerdo con la Ley de 20 de junio de 1837, que era la Ley vigente. Pero en el Decreto de convocatoria de elecciones, con los moderados en el poder, se establece que se realicen por distritos en vez de por provincias.

Dentro del primer período legislativo, el 11 de marzo del año siguiente, D. Pedro J. Pidal, Ministro de la Gobernación, presenta un proyecto de Ley electoral, que fue dictaminado por la Comisión correspondiente, pero que no llega a ser discutido por las Cortes, al plantearse una reforma más profunda que la referida a las normas electorales, referida a la misma Constitución de 1837. Presidía el Gobierno D. Ramón M. Narváez.

No corresponde en este trabajo analizar la reforma constitucional, que culminaría, como ya hemos recordado antes, el 23 de mayo de ese mismo año. Nos interesa en cambio referirnos al proyecto de Pidal, que tiene sus antecedentes y gran paralelismo en el proyecto que presentó $D$. Saturnino Calderón Collantes el 23 de marzo de 1840, siendo Ministro de la Gobernación, el cual fue aprobado por el Senado, pero el Congreso no llegó a nombrar Comisión, pues aquellas Cortes, elegidas en enero, fueron suspendidas en 25 de julio y disueltas el 11 de octubre.

Durante el período que contemplamos, es decir, el de vigencia de la Constitución de 1845, incluyendo también el de Pidal por la relevancia que tendría respecto a lo que seria la Ley electoral, se promulgan dos leyes electorales, seis proyectos de Ley electoral, una Ley de sanción penal, precedida de un proyecto de disposiciones penales. $Y$ entre el primero y el segundo período de vigencia de la Constitución, con la Constitución no promulgada de 1856, un proyecto de Ley electoral, presentado por D. Pedro Escosura el 7 de mayo de 1856.

Analizaremos en nuestro trabajo el contenido de estas dos leyes y de los indicados proyectos, si bien no incidiremos demasiado en el de 
1856, por estar fuera del contexto constitucional que nos hemos marcado, ni tampoco en la Ley de sanción penal o en el proyecto antecedente, por cuanto serán objeto de un trabajo singular.

No parece útil presentar un enunciado previo de las leyes y proyectos de Ley que sirva de guión cronológico de nuestro comentario subsiguiente. Pensamos en ese orden porque creemos que, dentro de los avances y retrocesos, va marcando la sucesiva ampliación del cuerpo electoral. Ampliación que eclosionará con la Revolución del 1868 y su Decreto de 9 de noviembre estableciendo el sufragio universal masculino.

\section{Leyes y Proyectos de Ley electoral de 1845 a 1865}

10-03-1845: Proyecto de Ley de Pedro J. Pidal

Con el primer periodo de vigencia de la Constitución:

18-03-1846: Ley electoral

07-11-1851: Proyecto sobre disposiciones penales (Bertrán de Lis)

01-12-1852: Proyecto de Ley electoral (Bravo Murillo)

Con el segundo período de vigencia de la Constitución de 1845:

30-05-1857: Proyecto de Ley electoral por insaculación (Marqués de Miraflores)

27-06-1860: Proyecto de Ley electoral (Posada Herrera)

09-12-1863: Proyecto de Ley electoral (F. Rodríguez Vaamonde)

21-02-1864: Proyecto de Ley electoral (A. Benavides)

22-06-1864: Ley de sanción penal

18-07-1865: Ley electoral

Con la Constitución "nonnata" de 1856:

07-05-1856: Proyecto de Ley electoral (Patricio de la Escosura). 
Leído este proyecto al Congreso y constituida la Comisión dictaminadora correspondiente, ésta presentaba su informe el 15 de abril de 1845, pero, como ya adelantábamos antes, no llegó a discutirse, pues se pasó a considerar como previa la reforma de la propia Constitución de 1837.

El proyecto adopta soluciones semejantes a las que se proponian en un proyecto moderado anterior, presentado por Calderón Collantes (el 23-3-1840).

En la exposición de motivos se dice que el mismo modifica la legislación vigente, es decir, la Ley electoral de 20 de junio de 1837, en seis aspectos principales. En primer lugar, aumentar el número de Diputados, que de 241 pasarían a ser 306 según el proyecto, al rebajarse la proporción entre el número de Diputados y el de habitantes de 1 por 50.000 a 1 por 40.000 . La población española, según el último censo, era de 12.171.959. Se argumenta que con ello el Congreso será más representativo, pues al ser más numeroso será "más resistente al empuje de los partidos" y, al propio tiempo, suplirá mejor las numerosas ausencias, ya que "muchos son los Diputados que por diferentes causas no pueden concurrir asiduamente a las sesiones". Nos parece interesante reflexionar sobre estos temas invocados: uno nos hace pensar en la poca consistencia de los incipientes partidos, poniendo por delante el interés individualista. No es, ni mucho menos, una crítica anticipada a los males de la partitocracia. El otro tema, pretextos aparte, es el vicio o irresponsabilidad de los elegidos, si es verdad que se producian tantas ausencias. Desgraciadamente, parece que no hemos mejorado mucho en esto. $Y$ ahora no se puede invocar que el cargo es gratuito.

$Y$ efectivamente, en el proyecto se establece la proporción indicada de 1 Diputado por cada $\mathbf{4 0 . 0 0 0}$ habitantes. A diferencia del proyecto de Calderón Collantes y de la propia Ley de 1837, se suprime la institución de Diputado suplente y la de Senadores, que pasan a ser vitalicios. El dictamen de la Comisión del Congreso incrementa más aún el número de Diputados, al rebajar la proporción a 1 Diputado por cada 35.000 habitantes, con lo cual el número sería de 349 Diputados. Estas modificaciones son perfectamente constitucionales, por cuanto la Constitución sólo pone un techo de mínimos, al determinar que se elegirá un Diputado a lo menos por cada cincuenta mil almas...n.

Por otra parte, se pretende modificar también las circunscripciones electorales. El sistema vigente de circunscripciones provinciales quedaría sustituido por el de distritos uninominales, eligiendo un Diputado cada 
uno. Se afirma que este sistema es más justo, pues la división provincial atenta a la igualdad del voto, pues cada votante no vota el mismo número de candidatos, según la provincia respectiva, "nombres cuya mayor parte son desconocidos o no gozan tal vez de toda su confianza". Con esta división, todos eligen el mismo número de Diputados, entendiendo que con ello se expresa más fielmente la voluntad del elector, se le facilita el ejercicio de su derecho, resultando más breve y expedito el procedimiento. $Y$, se argumenta aún, que con ello las elecciones parciales serán más fáciles, sin "conmover toda una provincia", como ocurre con la Ley en vigor.

También se argumenta que las "Juntas generales de escrutinio en las capitales de provincia han dado ocasión a quejas más o menos fundadas". En definitiva, se defiende la inmediatez de los escrutinios en distritos más pequeños, que supone ventajas de rapidez y mejor control. Las consecuencias "prácticas" para los que presentaban el proyecto resultan claras, si tenemos en cuenta el caciquismo rural que estaba en sus manos. Correspondería al Gobierno hacer la primera división en distritos, pero para modificarse ésta sería necesaria una Ley aprobada en Cortes.

Corresponderá al Gobierno designar la cabeza de cada distrito electoral. Y cuando se dividan éstos en secciones, para facilitar el ejercicio del sufragio, será el Jefe político de la provincia el que las determine. Para la división en secciones se requiere que cada una tenga al menos 200 electores, sin exceder de 600.

Otra innovación invocada en la exposición de motivos consistía en la reducción de la base electoral. Más Diputados, si, pero elegidos por menos electores. Se trataba de corregir los efectos del art. 7 de la Ley progresista, que, según la queja de los moderados, era la causa de que el derecho activo de sufragio fuera casi de carácter universal. Podemos ver en el estado adjunto de población-electores, que, aunque tener un par de yuntas para labrar exclusivamente tierras de cultivo propio era condición suficiente para ser elector, sin embargo el carácter censitario de esta Ley era muy acusado. Para los moderados, que dominan absolutamente estas Cortes, "la actual base electoral es demasiado amplia y vaga", "demasiados electores sólo sirve para que abunden aquellos que sin opinión propia... obedecen ciegos a unos cuantos que los manejan a su antojo...".

Para ser elector hay que estar incluido en el censo electoral. Y se exige, para tener derecho a ello, que pague 400 reales de contribución directa, frente a los 200 reales que se venían exigiendo, excluidas otras componendas. Sin embargo, se sigue admitiendo la composición con bienes de la esposa o de los hijos menores. También se admiten determinadas capacidades con tal que paguen la mitad de la contribución in- 
dicada, así como los empleados, en activo o no, que tengan un sueldo anual de 15.000 reales (arts. 14 y 16 del proyecto). Si en un distrito no se alcanzase un número de 150 electores, se completará este número con los mayores contribuyentes, incluyendo a todos los que alcancen el nivel igual al del menor contribuyente admitido. En la Ley de 1837 se exigía un número minimo de 300 electores por Diputado. Es decir, se reduce ahora a la mitad la proporción exigida como mínima.

Se requiere además, como en la Ley vigente, ser español, vecino del distrito $y$ de veinticinco años cumplidos.

Manifiestan los autores del proyecto su intención de cambiar el sistema de hacer las listas del censo, que pasan a ser permanentes, rectificándose cada dos años.

La confección de las primeras listas, así como su rectificación periódica, se atribuye al Jefe político de la correspondiente provincia, «por ser -según los proponentes- un principio de buen gobierno el no negar a la autoridad la legítima intervención que le corresponde siempre que se trate de ejecutar las leyes". Esta función venian desempeñándola las Diputaciones provinciales. Los Jefes politicos para formar las listas se valdrían de los Alcaldes y Ayuntamientos, de los datos de las oficinas de Hacienda $y$ de cuantos otros medios estimasen oportunos. A los efectos pertinentes, las listas se publicarian en los pueblos respectivos. La rectificación, dentro de un calendario tasado, consistiria en que los Alcaldes y dos Concejales elegidos por el Ayuntamiento remitirian al Jefe político una relación motivada de rectificaciones, distinguiendo los supuestos siguientes:

a) Bajas por fallecimiento.

b) Bajas por cambio de domicilio.

c) Bajas por haber perdido el derecho de voto.

d) Altas por reunir las condiciones exigidas $y$ no estar en las listas que se rectifican.

Prevista una modificación del sistema tributario, la primera rectificación se realizaría al aprobarse éste, sin esperar los dos años.

Corresponde al Jefe político resolver las reclamaciones, oido el Consejo provincial, cuyo dictamen no es vinculante. $Y$ en un plazo de 15 días naturales podrá recurrirse ante la Audiencia provincial respectiva. 
Las reclamaciones, firmadas y debidamente documentadas, se formularán por el interesado, y contra la inclusión o exclusión de cualquiera otra persona podrán proceder aquellos que se encuentren inscritos en las listas electorales (art. 25). Obsérvese lo que acabamos de reseñar y se apreciará una manifiesta contradicción en el referido art. 25 del proyecto de Ley.

En resumen, todo el calendario de confección del censo se desarrollaría desde el 1. de diciembre del año anterior al $1 . \circ$ de mayo del año en que corresponda rectificar las listas.

El derecho pasivo de sufragio, en la Ley de 1837, requeria para ser Diputado reunir las circunstancias prescritas en la Constitución (art. 55), y la Constitución sólo exige ser español, seglar, con veinticinco años, remitiéndose a la Ley electoral respecto a otras condiciones. Y ésta ya hemos visto que no exige ninguna especial. Por lo que supuestamente no podría exigirse un nivel de renta superior al de los propios electores. En el proyecto sí se exige una renta determinada, de más cuantia que para ser elector. Concretamente, se requiere una renta de 12.000 reales que provenga de bienes raíces, o pagar 1.000 reales de contribución directa.

Los altos cargos no pueden ser Diputados del distrito sobre el que tienen jurisdicción, y si fueren elegidos en otro distrito tienen que optar. Se exceptúan de tal incompatibilidad los que tengan su empleo en Madrid (arts. 8, 9 y 10). El plazo para ejercitar la opción es un mes. En el dictamen de la Comisión se amplió la incompatibilidad hasta seis meses después de haber cesado en el cargo.

Si fraude puede darse en la confección del censo, impidiendo acceder a él a los contrarios o conservando a los fallecidos, para fines ulteriores, enorme importancia tiene la formación de las mesas electorales, la emisión del voto y los recuentos ulteriores. Pedro J. Pidal, hombre de carácter irritable, impulsivo y agresivo, pretende en su proyecto un mayor control del Gobierno.

En la Ley de 1837, el primer día señalado para la elección, a las nueve de la mañana, bajo la presidencia del Alcalde, se procedía a elegir por $y$ de entre los electores presentes un Presidente y cuatro secretarios escrutadores. En el proyecto, el Presidente es el Alcalde o quien haga sus veces, $y$ auxiliado por dos electores designados por él se procede a elegir los cuatro secretarios escrutadores. La Comisión atribuye un tiempo de dos horas para constituir la mesa, frente a la hora prevista en el proyecto. Para la elección de éstos cada elector presente propondría sólo dos nombres, resultando elegidos los cuatro más votados. Y si no resultaran elegidos todos los secretarios, serían completados por designación 
de los electos con el Presidente. De alguna manera con este procedimiento se salvaguarda la presencia de las minorías. Pero la clave del control del Gobierno radica en que se reserva en la persona del Alcalde, que no es electivo, la presidencia de la mesa electoral. La Comisión dictaminadora también ratificó tal propósito. En palabras de la exposición de motivos, esta forma de componer la mesa se pretende para evitar la lucha por su conquista, $y$ "para evitar fraudes en las operaciones electorales y asegurar a todas las opiniones la libre emisión del voto".

La papeleta de voto sería entregada por el Presidente, rubricada por él. Y el elector, dentro del local y a la vista de la Mesa, escribirá por sí o hará escribir por otro elector el nombre del candidato a quien dé su voto, y el Presidente, a la vista del propio elector, depositará ésta en la urna. Piénsese en la capacidad de coacción de un Alcalde del gobierno en el poder para intimidar a un elector respecto al signo del voto, cuando, ante él y con la papeleta que le acaba de entregar, el elector debe formalizar su voto.

Este proyecto es el importante antecedente de la Ley que vamos a analizar a continuación. $Y$ por ello nos hemos detenido ampliamente en su consideración.

Relación comparativa de población, electores y votantes

\begin{tabular}{llcccc}
\hline Años & Censo civil' & Electores $^{2}$ & $\%$ & Votantes & $\%$ \\
\hline 1837 & 12.161 .882 & 257.984 & 2,12 & 143.026 & 55,43 \\
1839 & & 376.255 & 3,09 & 243.108 & 64,61 \\
1840 & & 423.787 & 3,48 & 321.456 & 75,85
\end{tabular}

Con la C. de 1845:

\begin{tabular}{|c|c|c|c|c|c|}
\hline 1846 & 12.161 .882 & 97.100 & 0,79 & 64.548 & 66,47 \\
\hline 1850 & & 121.770 & 1,001 & 82.375 & 67,64 \\
\hline 1851 & & 122.700 & 1,008 & 86.312 & 70,34 \\
\hline 1857 & 12.162 .872 & 157.725 & 1,29 & 91.689 & 58,13 \\
\hline 1858 & & $160.952^{3}$ & 1,32 & 111.706 & 69,40 \\
\hline 18 & & 418.271 & 3,44 & 223.211 & 53,36 \\
\hline
\end{tabular}

1 Fuente: estado oficial adjunto a la Ley electoral.

2 Fuente: Caballero, Tomás Vicente y Sevilla Andrés.

3 Sanchez Agesta, en Historia del Derecho Constitucional, pág. 467, da para 1858 unas cifras ligeramente inferiores a las que he incorporado en mi cuadro (157.931 electores y 109.503 votantes). 
Las Cortes reunidas en 1844 inician la llamada "década moderada", presidiendo el Gobierno Narváez. Se aprueban leyes como la de Ayuntamientos, atribuyendo al poder ejecutivo el nombramiento de los Alcaldes; se disuelve la milicia nacional, que era la verdadera fuerza de choque de los progresistas, $y$, para ayudar a los poderes públicos en el mantenimiento del orden, se crea el cuerpo de la Guardia Civil. Esto refuerza las posibilidades de mantenerse los moderados en el poder. $Y$ los progresistas ya no volverían nunca más a dominar la situación.

Ya señalábamos que los acontecimientos en las Cortes evolucionaron hacia una reforma constitucional, por lo que tuvo que aplazarse la reforma de la Ley electoral. Narváez, el 4 de julio de ese mismo año, convoca Cortes para la reforma de la Constitución de 1837. Esta actividad constituyente se prolonga hasta el 23 de mayo del año siguiente, cuando se promulga la Constitución de 1845 . No creemos que fuera necesaria la reforma realizada y ya adelantamos nuestra opinión sobre el peligroso precedente que ello suponía. En cierta medida, la Constitución de 1837 era una obra de conciliación y sus enunciados permitían que con cambiar la Ley electoral hubiese sido suficiente para satisfacer los distintos objetivos partidarios de progresistas y conservadores. Tanto es así, que en aquellas Cortes de composición moderada, sin presencia significativa de los progresistas, un sector de los propios moderados, los puritano-constitucionales, como Pastor Díaz, Pacheco e Istúriz, se opusieran a la pretensión de reforma, por considerarla innecesaria y peligrosa.

A pesar de todo, la Constitución de 1845 vino a regir durante más de veinte años, alcanzando una estabilidad no esperada. Es, por otra parte, el modelo más característico de todo el periodo de representación censitaria. $Y$, por supuesto, durante su vigencia el criterio restrictivo de conceder el derecho de voto alcanzó su mayor rigor. Frente al principio de la soberanía nacional prevalece el de "constitución histórica-dual". En el dictamen del proyecto de reforma constitucional se dice que "Las Cortes con el Rey son la fuente de las cosas legítimas" (vid. SÁNCHEZ AGESTA, op. cit.). El poder constituyente, en consecuencia, no se basa en la soberanía popular, sino en el principio dual Rey-Cortes. El Senado, como ya vimos anteriormente, se hace de designación real. $Y$ el Congreso prolonga su mandato a cinco años, frente a los tres años precedentes.

Con tan distinta extracción, las dos Cámaras cuentan con paridad de atribuciones, lo cual permite al Gobierno con el Rey bloquear los acuerdos del Congreso cuando lo estime conveniente. Pues un Senado con ilimitado número de miembros puede remodelarse conforme a lo que convenga al Gobierno de turno. 
Si bien la facultad de convocar a Cortes continúa como de competencia Real (art. 26 de la Constitución), se suprime la exigencia constitucional que garantizaba la reunión anual obligatoria de las Cortes el 1..$^{\circ}$ de diciembre, si el Rey no las hubiera reunido antes de tal fecha (art. 27 de la Constitución de 1837).

Con la Ley de 1845 los distritos electorales serán uninominales, uno por cada 35.000 habitantes y por restos que alcancen la mitad de la cifra anterior. Corresponde al Gobierno hacer la división de las provincias en distritos, pero realizada ésta, para modificarse debe hacerse por Ley. Quedaba establecido por la propia Ley el número de Diputados y de distritos correspondientes a cada provincia, según el estado adjunto a la misma, con la misma fuerza de Ley (arts. 3 y 36 ).

Para Ríos ROSAS, la fijación por Ley del número de Diputados evitaría que las provincias formularan interminables reclamaciones sobre cuántos les correspondían, al relacionar su base de población y el número de Diputados que pudiera corresponderles (Diario de Sesiones 29/1846, pág. 542).

Rige en esta Ley el mismo principio de división en Secciones, para facilitar la votación, pero el límite de 200 electores por Sección, como mínimo, no es imperativo en esta Ley, sólo indicativo, al recomendar que la división se haga "procurando que cada una conste de 200 electores a lo menos" (art. 38). Como en el proyecto Pidal, corresponde al Jefe politico determinarlas y su posterior rectificación al Gobierno. Para ORENSE, la división en secciones podría conducir a abusos y actos de arbitrariedad, por lo que se opuso a ello, aunque inútilmente (Diario de Sesiones 32/46, pág. 587).

La normativa sobre las listas del censo electoral también es idéntica a la propuesta del proyecto Pidal. Serán permanentes, de rectificación bianual, a cargo del Jefe político, valiéndose de los mismos instrumentos, todo tal cual ya ha quedado expuesto antes. De tal manera que estando las listas y su rectificación en manos del poder ejecutivo, la posible manipulación interesada, con inclusiones o exclusiones intencionadas, queda a su alcance. $Y$ nos consta que se aprovechó, dentro de las distintas técnicas de fraude electoral que abundaron en todo el siglo XIX. Durante la discusión en el Congreso, COIRA, en esta línea de interpretación, incluyendo a los Alcaldes, llega a decir que «en esta Ley el Alcalde lo hace todon (Diario de Sesiones del 4 de febrero/46, pág. 532).

En la rectificación del censo deben tenerse en cuenta los supuestos de pérdida o adquisición del derecho electoral como consecuencia de modificarse las circunstancias personales de renta, domicilio, incapaci- 
dades, o por fallecimiento, que puedan ser causa de baja o de alta en el mismo. El Jefe político, sobre nota del Alcalde $y$ dos concejales del respectivo Ayuntamiento, aparte de otros datos obtenidos de Hacienda y de otras dependencias que estime convenientes, hace la primera rectificación de las listas. El Ayuntamiento envía su nota en la primera quincena de diciembre con los pormenores idénticos al proyecto Pidal. Publicada la rectificación en la primera quincena de enero, se adjunta a la misma listas de excluidos e incluidos y el concepto que lo motiva, dentro de los cuatro supuestos previstos por el artículo 21 de la Ley (fallecidos, cambio de domicilio, pérdida del derecho y adquisición del mismo).

Las reclamaciones pueden formularse hasta el $31^{-}$de enero. En la Ley ya no se reproduce el disparate contradictorio del art. 25 del proyecto de Pidal. Ahora, con la condición de que las reclamaciones deben ir documentadas (art. 25), se reconoce el derecho a reclamar de todo aquel que haya sido excluido y crea reunir las condiciones para ser elector. $Y$ se admite también el derecho de los que son electores reconocidos (los individuos inscritos) para reclamar sobre la inclusión o exclusión de cualquiera otra persona.

Los excluidos tendrán de plazo para reclamar hasta el 5 de marzo siguiente, mediante instancias documentadas ante el Jefe político. Éste, oído el Consejo provincial, resuelve libremente y ordena publicar las listas con la segunda rectificación, el 1. de abril inmediato. Por último, queda el recurso ante la Audiencia propia, hasta el 1. del mismo mes, la cual dictará sentencia inapelable dentro del mismo mes y devolverá el expediente al Jefe político, para que éste haga en vista de la sentencia las rectificaciones procedentes. El procedimiento es de oficio, con vista oral, teniendo previamente el Ministerio fiscal y la defensa un día cada uno para instruirse. Queremos destacar en esta normativa la exigencia del recurso ante la Audiencia: "Sólo podrán interponerle aquellos sobre cuyas reclamaciones o instancias hubieren recaído las resoluciones mencionadas", es decir, las tomadas por el Jefe político. Esto significa que un silencio de la autoridad o un "extravio" de papeles era causa suficiente de indefensión, que dejaría al reclamante sin que se le reconociese su presunto derecho electoral (arts. 30 y 31 ).

Finalmente, el 15 de mayo el Jefe político hace públicas las listas definitivas, que quedan inalterables durante el bienio correspondiente, sin que se admitan otras rectificaciones. Éste servirá para todas las elecciones que se celebren hasta la próxima rectificación. El derecho de voto queda condicionado a estar en el censo electoral y pueden quedar irremediablemente excluidos por dos años individuos que realmente deberian tener tal derecho y que les ha podido ser escamoteado con medidas fraudulentas, pero irrecurribles. 
La introducción del recurso ante la Audiencia, pretendidamente para dar entrada a un poder independiente, resultó de dudosa eficacia. Para muchos Diputados de la época fue considerada como una función anómala que, o se abusaría de ella si era de oficio, o se prescindiría casi totalmente si habia costas. CHURRUCA advirtió al Congreso que la magistratura española, en lugar de ser inamovible, conforme a la Constitución, sufría "una interinidad indefinida" y quedaba sujeta por ello a la gracia del Ministerio de Justicia (Diario de Sesiones, n. ${ }^{\mathrm{9}}$ 32/1846, pág. 584).

La Comisión dictaminadora se mostraba reticente a las cuestiones planteadas, accediendo finalmente a aceptar la gratuidad del recurso ante la Audiencia, adicionándose al final del párrafo cuarto del art. 31 del proyecto que "todos estos procedimientos se entenderán de oficio". Y así quedó en la Ley, evitando que el pago de costas inhibiera de actuar.

Pero, ¿qué condiciones eran exigibles para estar en el censo?, condición para ser efectivamente elector. Siendo español, había que estar domiciliado en el distrito electoral donde estuviese inscrito en las listas, de 25 años de edad y gozar de una determinada renta (art. 14 de la Ley). Una finalidad básica de los moderados era reducir drásticamente el censo, que consideraban había crecido progresiva y aceleradamente con la aplicación de la Ley de 1837, que, afirman, había llevado la ampliación del sufragio a darle un carácter casi universal. Por el cuadro que hemos preparado antes, se ve claro lo descaradamente mendaz de tal afirmación. En el momento de más expansión del sufragio con la Ley progresista, éste alcanza el 3,48 por ciento, a pesar de los supuestos de reconocimiento del derecho por poseer una yunta o disponer de cierta vivienda en renta.

La nueva Ley admite como posibles electores sólo a aquellos contribuyentes que paguen 400 reales de contribución directa, justo el doble que la exigida por la Ley de 1837, y, como en otros proyectos de los moderados, se admiten también determinadas capacidades que paguen la mitad de la contribución señalada antes. Se eliminan todos los demás supuestos. Se sigue admitiendo como composición la renta y bienes de la esposa y de los hijos no emancipados.

Cada distrito debía tener al menos 150 electores (la mitad de la exigida por la Ley precedente) y si aplicadas las reglas anteriores no alcanzasen dicho minimo, se extendería el derecho a los mayores contribuyentes hasta completarlo, admitiendo a todos aquellos que paguen la misma contribución que el menor contribuyente admitido (arts. 14 a 17). La Comisión consideró nefasta la solución de admitir a los mayores contribuyentes para completar el número minimo establecido, por conside- 
rar que puede provocar el sectarismo local, pero lo acepta para aquellos casos en que de lo contrario podría quedar un distrito sin representación (Diario de Sesiones de 31/01/46, apéndice Dictamen al proyecto).

Las condiciones del sufragio pasivo dejan de igualarse con las propias del derecho activo, para endurecerse más. Son necesarios 12.000 reales de renta o 1.000 reales de contribución directa para ser candidato a Diputado. Se admite la composición de bienes con los de la esposa e hijos dependientes del candidato, y la parte proporcional de su interés en sociedades, compañías o empresas.

Las incapacidades, tanto para ser elector como para ser Diputado, son las siguientes (arts. 11 y 18):

1. Procesados criminalmente, en los que hubiere recaido auto de prisión.

2. Los que por sentencia judicial hayan padecido penas corporales, aflictivas o infamatorias, sin haber sido rehabilitados.

3. Los sometidos a interdicción judicial por incapacidad.

4. Los fallidos o en suspensión de pagos o con sus bienes intervenidos.

5. Los apremiados como deudores a los caudales públicos.

Son idénticas a las de la Ley anterior.

Las incompatibilidades casi desaparecen, para dar paso a muchos cargos públicos de gobierno que eran incompatibles. Sólo quedan incompatibles los siguientes cargos:

1. Capitanes generales de provincia.

2. Comandantes generales de departamentos de Marina.

3. Fiscales de Audiencias.

4. Jefes políticos (Gobernadores civiles).

5. Intendentes de Rentas (Delegados de Hacienda).

Pero con las siguientes salvedades:

a) Se exceptúan los que tienen tales cargos en Madrid.

b) En los demás supuestos pueden presentarse a elecciones en distritos fuera de la esfera de su jurisdicción. 
c) Si son elegidos, tienen un mes de plazo para optar entre el cargo de Diputado o el empleo que desempeñan.

En la normativa anterior, aparte de la mayor amplitud de incompatibilidades, no pueden presentarse a elecciones.

En la nueva Ley, se considera perturbadora la elección de suplentes que regulaba la Ley de 1837 y se suprime, estableciéndose únicamente la elección de Diputados titulares.

La Comisión del Congreso, en su dictamen, considera que elegir un solo Diputado, sin suplentes, supone aplicar con más plenitud el principio de elección directa. Y para conseguir una representación más numerosa en el Congreso reducen la base de proporcionalidad entre Diputados y población a razón de 1 Diputado por cada 35.000 habitantes, frente al proyecto del Gobierno, que era de 1 por 40.000 (en la Ley de 1837 era 1 por 50.000$)$.

Fue motivo de amplias deliberaciones en el Congreso el tema de la composición de la renta con bienes de la esposa e hijos, junto al principio de rectificación bienal de las listas electorales, dentro del criterio restrictivo que impera en la Cámara para reducir el número de electores, ya que puede darse una gran disminución de renta al perder la esposa o emanciparse un hijo, que, sin embargo, permite la posibilidad de seguir siendo elector o Diputado hasta que se produzca la consabida rectificación del Censo, que, mientras, es inalterable. También habia fuerte discrepancia sobre la equivalencia entre renta y contribución exigida. Sin embargo, prevaleció el criterio del Gobierno, hecho suyo por la Comisión.

Para ser Diputado por un distrito no se exige estar domiciliado en él. Es proclamado aquel que obtiene la mayoría absoluta. Cuando ésta no se dé, se procede a una segunda vuelta entre los dos más votados en la primera. $Y$ si hubiera empate en esta segunda elección, se desempata por sorteo.

Ya se hizo notar en la discusión de la Ley, que no queda suficientemente claro si la decisión por suerte en caso de empate se refería sólo a la segunda vuelta o también en la primera elección, si quedaran más de dos candidatos. A pesar de esta falta de claridad, los ponentes no aceptaron cambios y la Ley quedó con esa ambigüedad reconocida.

Alargando el mandato del Diputado de tres a cinco años, que establece la nueva normativa, distanciará más a los elegidos de sus electores. 
El control de la mesa electoral tiene una importancia capital para poder "fabricar resultados". En la Ley anterior el Presidente era elegido; ahora, desde el momento de constituirse la mesa provisional ya es presidida por el Alcalde o quien le represente, y a él o su representante le corresponde la presidencia definitiva. Recordemos que la designación para Alcalde es de carácter gubernativo. Presidida asi la mesa, es indudablemente más fácil controlarla, empezando por controlar la elección de los cuatro secretarios escrutadores que deben constituir la mesa junto con su Presidente.

La mesa provisional, junto con el Alcalde, la forman los dos electores más jovenes y los dos más viejos de los presentes en el local de elecciones, a primera hora del primer día de elecciones. Pero en caso de duda sobre la edad, decide el Presidente, facultad que en aquella época, con dificultades probatorias si se cuestionaba la edad, podía permitir al Presidente cometer la arbitrariedad más útil a sus fines. Ni siquiera llevar la partida de bautismo le será suficiente a un oponente para ser designado contra la voluntad del Alcalde.

Seguidamente los presentes proceden a elegir dos, para que sean elegidos como secretarios de la mesa definitiva los cuatro con más votos. Esta votación termina a las doce, salvo que antes hayan votado todos los electores del distrito. Los cuatro elegidos deben serlo de los presentes al cerrarse la votación, y ahí puede también haber sorpresas fraudulentas. Basta con cerrar la votación en un momento conveniente, alegando que ya votaron todos. Pues la mesa, totalmente controlada, permitirá hacer que la lista de los que han votado sea "completa". Si no resultaran elegidos todos los secretarios escrutadores, serán completados entre los presentes por el Presidente y los electos. Constituida la mesa definitiva empezará la votación para elegir Diputado, que durará hasta las cuatro de la tarde, seguida de escrutinio, actas y destrucción pública de las papeletas. El día siguiente continúan las elecciones de ocho de la mañaana a las cuatro de la tarde, cumpliendo las mismas formalidades. El resumen general de cada sección se hace al tercer día, $y$ tres días después se hace el resumen general en la cabeza de distrito y se proclama el vencedor. Si no hubiere secciones se proclama Diputado al candidato vencedor con mayoría absoluta. En segunda vuelta, recordemos, van los dos de más votos, resolviendo a suerte los empates.

Nos interesa destacar la afirmación del art. 47 de la Ley, de que "la votación será secreta". Pero el procedimiento no puede ser más mediatizador de lo que se proclama. La papeleta la entrega el Presidente-Alcalde, rubricada por él, a cada elector. Y éste debe escribir, por sí u otro elector por él, en dicha papeleta el nombre del candidato que elige. Esta operación hay que hacerla "dentro del local y a la vista de la Mesa». Po- 
co importa que el elector devuelva "la papeleta doblada al Presidente», resulta claro la falta de garantías de secreto, y, para aquella época, la falta de libertad en el ejercicio del derecho; pero es que, además, admitir el voto por encargo vulnera el secreto que se pretende respetar. Pues bien, un tema tan importante para la garantía del ejercicio del derecho de voto, ni siquiera se discutió en el Congreso.Si al plantear esta cuestión se pensaba en iletrados, mejor hubiera sido adoptar un sistema basado en símbolos fáciles de escoger. O bien negar el derecho de voto, ya tan restringido, a quien no pudiese formularlo personalmente.

Para dejar mejor atado el resultado que se "cociere", el art. 62 de la Ley confiere al Presidente, escrutadores de sección y vocales de junta de distrito, a pluralidad de votos, la facultad de resolver cada día de elección, definitivamente, cuantas dudas y reclamaciones se susciten. Poco importa que se hagan constar en el acta, así como las resoluciones motivadas o las protestas consiguientes. Nada de ello va a tener valor práctico alguno. Más bien parece un sarcasmo, dada la magnitud de la facultad discrecional atribuida a un órgano difícilmente imparcial. Esto, más que un disparate legislativo, parece una medida interesada para asegurar unos resultados electorales favorables al Gobierno de turno. Y así se fueron celebrando elecciones ganadas desde el poder. Tampoco la Cámara discutió lo más mínimo el contenido de este artículo. Más aún, al Diputado $\mathrm{Sr}$. Polo aún le parecen insuficientes las restricciones y garantías para dirigir las elecciones a su conveniencia y manifiesta a la Cámara sin empacho: "Disminuyamos en lo posible el número de elegibles, disminuyamos en mucho el número de electores, y sea franca, legítima y grande la influencia del Gobierno en las elecciones... Lo primero es hacer leyes que no sea necesario para gobernar desatenderlas o violentarlas" (Diario de Sesiones 29/46, pág. 529). Así es difícil que un Gobierno pierda las elecciones, pero refleja la inmoralidad política, irrespetuosa incluso con un "electorado de intereses".

Hasta la "oposición" ha sido prevista y cuadriculada en sus dimensiones, a menudo presente sólo simbólicamente. Pero la oposición también sabe que ganado el poder con intrigas palaciegas, podrá a su vez tomar la revancha, convocando unas elecciones a su medida.

Como dato pintoresco, o contradictorio, reseñamos que la Ley castiga con la expulsión del local y privación del voto activo y pasivo a quien se presente con arma, palo o bastón, pero permite que las autoridades usen en las Juntas "su bastón" (art. 66). Será porque en la pugna electoral la persona investida de autoridad pública no se deja llevar de la pasión y practica la imparcialidad, ¿o acaso porque teniendo otros recursos para alcanzar sus objetivos, no necesite usar del bastón para romper la urna? 
Menos relevancia tiene la referencia a Canarias, autorizando al Gobierno para que establezca plazos más flexibles, teniendo en cuenta sus circunstancias particulares.

Aparte de la restricción tan grave del derecho del voto, no hemos encontrado apenas motivos de alabanza de esta norma, y no nos vale el argumento de que la misma sea imitación de la Ley francesa de 19 de abril de 1831.

Siendo Ministro de la Gobernación el Conde de San Luis, se aprobó el 16 de febrero de 1849 una Ley sobre los casos en que procede celebrar elecciones parciales de Diputados en Cortes. En la misma se dispone que habrá elecciones parciales por acuerdo del Congreso, o bien cuando, estando cerrada o suspendida la legislatura, se produzcan renuncias o fallecimientos. En tal caso se da un plazo de diez días al Gobierno para que las convoque. Las elecciones deberán celebrarse entre los 20 y los 30 días de su publicación. Por lo demás, se remite erróneamente al art. 5 de la Ley electoral, cuando lo que quiere decir es que se celebrarán conforme al Título $\mathrm{V}$.

Gobierno de Bravo Murillo. 1851-1852

Disueltas las Cortes de 1846 el 4 de agosto de 1850, se celebran nuevas elecciones el $\mathbf{3 1}$ del mismo mes, y las mismas abren solemnemente sus sesiones el 31 de octubre. Presidía el Gobierno RAMÓN M. NARVÁEZ y era Ministro de la Gobernación LUIS J. SARTORIUS, Conde de S. Luis. En las elecciones, la intervención escandalosa de éste para conseguir una amplia mayoría resultó tan fraudulenta que motivó que se denominara a la Cámara constituida con el mote de Congreso de familia. Era Ministro de Hacienda JUAN BRAVO MURILLO, que ante la situación del país pretendió reducir gastos, sin que el Gobierno se lo permitiera, por lo que decidió dimitir en noviembre de 1850. La opinión pública en esta ocasión estuvo de su parte, y poco después, el 10 de enero de 1851, fue Narváez el que se vio forzado a dimitir. Fue sustituido en la presidencia por Bravo Murillo, el 14 del mismo mes.

Este gran estadista pretendió recomponer la situación del país, poniendo coto al intervencionismo político de los militares, tratando de remediar los excesos parlamentarios, así como reorganizar la administración y la economía. Muchos logros se deben a esta etapa. Las escandalosas Cortes de 1850 fueron disueltas por el Gobierno el 6 de abril y celebradas nuevas elecciones el 10 de mayo. El 1.. de junio fue la 
apertura solemne de las nuevas Cortes. Junto a su buen hacer como estadista, las ideas reaccionarias de Bravo Murillo le llevaron a enfrentamientos con moderados y progresistas, que temían su excesivo rigor. Las Cortes se reunieron con intermitencias, sufriendo varias suspensiones. Finalmente, fueron reunidas el 1 de diciembre de 1852, iniciando la segunda legislatura de las mismas. El mismo día se produjo el choque entre Congreso y Gobierno e infligieron una seria derrota a éste, que optó por disolverlas. Planteada la cuestión de confianza ante la Reina, ésta resolvió a favor del Gobierno y al día siguiente era leído a ambas Cámaras el Real Decreto de disolución. Pero, sintiéndose Bravo Murillo cada vez más acorralado por sus enemigos políticos, y notando menor apoyo en la Corona, dimitió el 14 de diciembre.

A esa época corresponden diversos proyectos de Ley, entre los que se encuentran uno sobre disposiciones penales en materia de elecciones, presentado el 7 de noviembre de 1851 por D. Manuel Bertrán de Lis, Ministro de la Gobernación, y otro sobre las elecciones a Diputados a Cortes, publicado en la Gaceta de Madrid al día siguiente de ser disueltas las Cortes, presentado, junto a otros ocho proyectos, por el propio Presidente del Consejo de Ministros, D. Juan Bravo Murillo. Pretendía Bravo Murillo que sus nueve proyectos de reforma, celebradas nuevas elecciones, las nuevas Cortes tomaran conocimiento de ellos y los aprobasen sin enmiendas o los rechazasen en una sola discusión y votación. Al menos, en lo que se refiere al proyecto de Ley electoral, prescindiendo de sus contenidos antidemocráticos, tiene tal cantidad de disparates técnicos, que nos parece otro disparate tal pretensión. (Los nueve proyectos eran: 1. Sobre la Constitución; 2. Sobre el Senado; 3. El indicado sobre elección de Diputados; 4 . Régimen interior de los Cuerpos colegisladores; 5 . Relaciones entre Senado y Congreso; 6 . Seguridad de las personas; 7. Inviolabilidad de la propiedad; 8 . Orden público, y 9 . Grandes y títulos del Reino).

Cortes de 1850 y de 1851

\begin{tabular}{lcccc}
\hline Elección & Apertura & Suspensiones & Clausura & Disolución \\
\hline $31-08-50$ & $31-10-1850$ & & & $06-04-1851$ \\
$10-05-51$ & $01-06-1851$ & $30-07-1851$ & & \\
& $05-11-1851$ & $09-12-1851$ & $07-01-1852$ & \\
& $01-12-1852$ & & & $02-12-1852$ \\
\hline
\end{tabular}


Presentado al Congreso, el 7 de noviembre de 1851 por el Ministro de la Gobernación D. Manuel Bertrán de Lis, un proyecto de Ley estableciendo disposiciones penales en materia de elecciones, el mismo no llegó a prosperar. Pero sirvió de antecedente de lo que en 1864 seria Ley de procedimiento $y$ sanción penal en los delitos electorales. También supone un verdadero catálogo del fraude en materia electoral que se practicaba en esta época.

El rigor del Gobierno Bravo Murillo y el reciente escándalo del Congreso de familia fueron motores para intentar moralizar la vida política y parlamentaria. En la exposición de motivos de este proyecto se alude a la necesidad de ensanchar las incompatibilidades para ser Diputado (recordemos la posibilidad que concede la Ley de 1846 de que la mayoría de los altos cargos puedan ser Diputados, y aun de que los incompatibles puedan ser elegidos fuera de su jurisdicción, para a continuación optar por el cargo de Diputado o por el que ostenta), anunciando que el Gobierno presentaría próximamente un proyecto de Ley sobre tal cuestión. Y también se señala que es necesario completar la Ley electoral con sanciones penales que frenen y castiguen los abusos en materia de elecciones. A este último objetivo se encaminaba el proyecto presentado.

Las figuras delictivas en materia de elecciones se asimilan a las establecidas en el Código Penal, a cuyo articulado se remite para establecer las penas. Así las remisiones, cuando una figura no está contemplada penalmente, se basan en la analogía. Pretende remediar tanto los abusos de la autoridad como los que puedan cometer los particulares.

Como pena común para los delitos que se contemplan, se incluye la pena de privación temporal del voto activo y pasivo (art. 7.9). Sin embargo, no matiza ni establece reglas para concretar en cada caso el alcance de dicha pena. Se contempla la posibilidad de que tal privación del derecho electoral se aplique a todo un distrito o a una sección del mismo, cuando en las elecciones ocurra algún tumulto o cuando los actos punibles se hayan repetido y provocado nulidad declarada por el Congreso (art. 9.9).

Se castiga como delito la inclusión o exclusión de las listas electorales hecha indebidamente, bien por no considerar datos oficiales o por desatender alguna reclamación oportuna y legal (art. 1).

Los funcionarios públicos incurren también en delito cuando hagan salir de su domicilio a un elector en los dias de elecciones, o impe- 
dirle votar mediante alguna disposición ilegal; alterar los plazos legales de los actos electorales; rehusar dar copia certificada de documento útil para probar la capacidad o incapacidad de cualquier elector (art. 2, s.).

También define el proyecto el concepto de funcionario a los efectos del mismo. Lo son todos los que están comprendidos en el art. 331 de Código Penal vigente $y$ aquellos que en materia electoral tengan cargo público accidental, sea por nombramiento real o por elección popular (art. 4).

En cuanto a los electores, se castigaría votar más de una vez en una elección; suplantación de otro para votar por él; cualquiera otra falsedad que se cometiere, y finalmente cuando alguien fuerce a un elector a votar o a abstenerse (arts. 5 y s.).

Se pretende incorporar una garantía mayor de publicidad del censo, obligando a la autoridad a imprimir las listas electorales, poniéndose a la venta del público un ejemplar por cada diez electores, como mínimo.

Al no prosperar el proyecto, habrá que esperar al ya citado de 1864, que presentó CÁNOVAS y que tendrá mejor fortuna al llegar a ser Ley el 22 de junio de dicho año.

\section{Proyecto de Ley electoral de Bravo Murillo}

Debido a la disolución de las Cámaras, los proyectos de reforma que tenia preparados Bravo Murillo, a los cuales ya nos hemos referido antes, no pudieron llegar a presentarse en el Congreso y, para que la opinión pública pudiera juzgar por si misma, fueron publicados por Real Decreto en La Gaceta de Madrid al día siguiente de la disolución de aquéllas, es decir, el 3 de diciembre de 1852. Ya sabemos que uno de los proyectos pretendía la reforma de la Ley electoral. Proyecto que mereció la repulsa de la Cámara antes de ser oficialmente conocido por ésta. En su conjunto, el proyecto es más restrictivo que la Ley vigente, pero conservando muchos de sus planteamientos.

Según dicho proyecto, las elecciones serían también por distritos uninominales, como en la Ley vigente, pero se reduce su número a 171 , frente a los 349 de ésta. Se acompaña al proyecto un estado de distribución provincial de diputados. Al Gobierno correspondería dividir las provincias en distritos electorales y determinar su cabeza, ajustándose al número establecido en proyecto. En el estado de distribución de Diputados 
por provincias se recoge como censo civil el mismo de la Ley de 1846, pero la proporcionalidad en relación con la población provincial respectiva es irregular y arbitraria; ya sin limitaciones legales para establecer los distritos, el Gobierno podría discrecionalmente establecer éstos sin someterse a una proporcionalidad concreta. Ponemos algún ejemplo de esta falta de rigor distributivo:

Cortes de 1850 y de 1851

\begin{tabular}{lcccc}
\hline Provincia & Población & $\begin{array}{c}\text { Diputados } \\
\text { Ley 1846 }\end{array}$ & $\begin{array}{c}\text { Diputados } \\
\text { Proyecto/52 }\end{array}$ & $\begin{array}{c}\text { Proporción } \\
\text { por habitante }\end{array}$ \\
\hline Álava & 67.523 & 2 & 1 & 1 por 67.523 \\
Albacete & 180.763 & 5 & 3 & 60.254 \\
Alicante & 318.444 & 9 & 5 & 63.688 \\
Almeria & 234.789 & 7 & 3 & 78.263 \\
Ávila & 137.903 & 4 & 2 & 68.951 \\
Badajoz & 316.022 & 9 & 5 & 63.204 \\
Baleares & 229.197 & 7 & 3 & 76.339 \\
Barcelona & 442.273 & 13 & 6 & 73.712 \\
Burgos & 224.407 & 6 & 3 & 74.802 \\
Cáceres & 231.398 & 7 & 3 & 77.132 \\
........ & & & & \\
Madrid & 369.126 & 11 & 5 & 73.825 \\
........ & & & & 52.471 \\
Sevilla & 367.303 & 10 & 6 & 75.280 \\
Valencia & 451.685 & 13 & &
\end{tabular}

Para ser elector hay que estar incrito en el censo, ser vecino del distrito correspondiente desde dos años antes, ser uno de los 150 mayores contribuyentes por contribución directa, o pagar la cuota mínima para alcanzar dicho número, o en su defecto los 150 domiciliados más pudientes. Esto último, sin una base objetiva de valoración, abriría paso al sectarismo local. Corresponde al Gobernador (antes denominado Jefe político) formar las listas siguiendo unos plazos semejantes a la Ley, pero sin condicionarle las fuentes de información. En el recurso a la Audiencia encontramos algo positivo, respecto a la norma vigente al establecer sin más condiciones que uen los diez primeros días de febrero, los que se sientan agraviados podrán recurrir..." (art. 33). La rectificación es bienal como hasta el momento. Se mantienen los mismos condicionantes de exclusión, publicidad, etc. 
Para ser candidato también se endurecen las condiciones. Se aumenta la edad exigida a 30 años y ser contribuyente por 3.000 reales, el triple de la exigencia vigente, si bien se reduce a 2.000 reales, si 500 reales corresponden a propiedad inmueble, y manteniendo los 1.000 reales actuales, si toda la renta procede de dicha clase de propiedad. Se amplía el número de incompatibilidades, si bien algunas de éstas permiten la opción entre cargos. Si se aceptase cargo o recompensa del Gobierno, obligaría al electo a someterse a reelección. A los candidatos que sean elegidos se les exigiría prueba documental de que reúnen las condiciones exigidas, debiendo presentarlas ante el Gobernador.

La Mesa será presidida por el Juez de partido judicial más antiguo, y a falta de Juez, por la persona designada por el Gobernador. Es decir, mal si se implica en actos políticos a los jueces, y peor si, en su defecto, es la autoridad gubernativa quien lo nombra. En definitiva, se seguiría con el Alcalde como Presidente de la mesa, en defecto de Juez, a menudo interino y supeditado en su nombramiento al Ministerio de Justicia. No es más alentador, por antidemocrático, que la designación de los cuatro secretarios escrutadores, en principio los cuatro electores presentes de menos edad, la decida realmente el Presidente de la mesa, por cuanto a él corresponde inapelablemente resolver las dudas.

La duración de las elecciones se reduce a un sólo dia, con no menos de ocho horas de duración. Se suprimen las secciones, realizándose la elección en la cabeza de partido. Dadas las incomodidades y dificultad para desplazarse desde muchos lugares hasta la cabeza de partido, esta medida favorecería la abstención y, seguramente, facilitaría la manipulación de resultados. vigente.

En otros aspectos la normativa electoral no varia respecto a la Ley

Dada la enormidad del fraude propio de la época, nos parecen positivas las disposiciones del proyecto que permiten a cualquier elector comprobar por sí la verdad de un voto (art. 53). Asimismo, que las papeletas de voto no fueran destruidas sino guardadas en el acto, en un pliego sellado $y$ suscrito por la mesa, para ser enviado inmediatamente, junto con las actas y proclamación de candidato, al Tribunal Supremo. No se excluye que con tan largo camino, el pliego fuera sustituido o modificado en su contenido.

Según el proyecto, correspondería al Tribunal Supremo aprobar las actas ateniéndose sólo a la legalidad documental.

Por primera vez se contempla un título expreso, el Título VI del proyecto, dedicado a la «sanción penal». Su contenido sigue la línea del pro- 
yecto de Bertrán de Lis, asimilando los delitos en materia electoral a las figuras delictivas del Código Penal. Sólo hay una novedad en este título: permitir que el Presidente de la Junta electoral prescinda de recurrir a la vía judicial en determinados supuestos y disponga contra el infractor, que salga del local de la Junta, detenerlo hasta diez días, o bien imponerle una multa que no exceda de 1.000 reales. Los supuestos eran dos: uno, al que se presente con armas, palo o bastón, y otro respecto al que a la entrada o dentro del local de elecciones perturbe el orden, cometa algún exceso o imposibilite el ejercicio pácifico del derecho de voto.

Aunque siguen a continuación los efímeros Gobiernos de Roncali (hasta abril de 1853), de Lersundi (hasta septiembre), del ultra Sartorius (hasta julio de 1854), el progresismo está en la puerta y agotada ya la década moderada.

Nueva vigencia de la Constitución de 1845

Las Cortes constituyentes elegidas el 4 de octubre de 1854 fueron disueltas el 2 de septiembre por D. Leopoldo O'Donnell, que había asumido el Gobierno el 14 de julio.

El agitado período de la Constitución «non nata» lo posponemos, con el fin de seguir el hilo del derecho electoral desarrollado durante la vigencia de la Constitución de 1845.

O’Donnell formó Gobierno con los moderados más progresistas y los progresistas más moderados. Diríamos que con un apoyo de centro. Esto sorprendió a los más exaltados de ambas tendencias, que en Madrid dieron una respuesta airada, levantándose en armas contra el Gobierno. Éste encomendó al ejército, al mando de los generales Serrano y De la Concha, reprimir la sublevación. Esto se consiguió el 16 de julio, en un sangriento enfrentamiento entre ambas partes. Hubo resonancias de la sublevación de Madrid en varias provincias, particularmente en Zaragoza, Barcelona, Valencia y Málaga, que también fueron reprimidas.

A partir de ahi, el Gobierno O'Donnell emprende la tarea de desmantelar lo hecho en el bienio precedente. Se disuelven y reorganizan los Ayuntamientos y Diputaciones, se disuelve la Milicia nacional (13 y 15 de agosto) y, lo que tiene más relevancia para nuestro estudio, disueltas las Cortes, por Real Decreto de 15 de septiembre se restablece la vigencia de la Constitución de 1845, si bien con un Acta adicional de carácter liberalizador, pero de corta vigencia. A ella nos referiremos en cuanto a su contenido en materia electoral. 
Pero los moderados prefieren para la "restauración" a D. Ramón Narváez y conspiran en palacio a su favor. Se consigue el objetivo el 12 de octubre del mismo año, aprovechando un baile en palacio. $Y$ pese a las seguridades recibidas por la Reina, O'Donnell queda desairado, siendo nombrado nuevo Presidente del Consejo de Ministros Narváez. Con éste quedaría derogada el Acta adicional y devuelta la vigencia plena de la Constitución moderada.

En materia electoral, estos Gobiernos no presentan ninguna iniciativa legislativa. Sólo durante el Gobierno de Narváez hay una iniciativa no gubernamental, a cargo de un Senador, el Marqués de Miraflores, pintoresca y regresiva, a la que no dedicaremos demasiado espacio, pues no lo merece.

El Acta adicional a la Constitución, aprobada por R. D. de 15-91856, al tiempo que se restablecía la Constitución, quedó derogada 29 dias después, por R. D. de 14 de octubre, sin que sus disposiciones llegaran a tener relevancia alguna. Había sido obra del ministro RíOS ROSAS, con el intento de liberalizar algo la Constitución de 1845.

En lo que hace referencia a las composición de las Cámaras, el Acta dedica el art. 3. ${ }^{\circ}$ al Senado, limitando su número inicial a 140 miembros y condicionando al Rey para nombrar nuevos Senadores a que sea en fechas en que estén abiertas las Cortes.

Respecto a los Diputados, deja a la Ley electoral que determine si éstos han de acreditar o no el pago de contribución o la posesión de renta, abriendo con ello la puerta a la posibilidad legal de prescindir de esta condición. En la misma línea "democratizadora" se enmarca la exigencia de que siempre que un Diputado admita cualquier empleo, aun de los de escala, deberá someterse a reelección (arts. 4 y 5 ).

Aún se dictó otra Ley condicionante de la Constitución, la Ley Constitucional de Reforma, de 17 de julio de 1857, que estuvo vigente hasta el su derogación por Ley de 20 de abril de 1864 . Se refiere a quienes serán Senadores por derecho propio y reitera la facultad del Rey de nombrar otros en número ilimitado de entre aquellos que pertenezcan o hayan pertenecido a determinadas categorías. Para los Grandes de España con renta de $\mathbf{2 0 0 . 0 0 0 ~ r e a l e s ~ p o r ~ b i e n e s ~ i n m u e b l e s , ~ l a ~ c o n d i c i o ́ n ~ d e ~}$ Senador será hereditaria, pudiendo a tal fin vincular los bienes necesarios.

Respecto a los Diputados, sólo se hace referencia a que la legalidad de las elecciones y la calidad de los individuos que componen el Congreso será decidida por la propia Cámara. 
El proyecto de elección por insaculación

El 30 de mayo de 1857 fue presentada en el Senado una proposición de Ley electoral. Fue su autor, repetimos, el Sr. Pando, Marqués de Miraflores, miembro de dicha Cámara.

Leída la misma ante el Senado, no fue tomada en consideración. Su autor volvió a insistir en la legislatura siguiente, con los mismos resultados que la primera vez. La singularidad de la proposición consistía en que se suprimian las elecciones y se procedía a designar los miembros del Congreso por insaculación. Con ello, según su autor, se conseguiría una mayor sencillez y economía de procedimiento.

La proporción entre Diputados y población sería de 1 por cada 90.000 habitantes o fracción de 40.000 . Basta compararlo con la drástica reducción de la representación pretendida por Bravo Murillo, para apreciar que frente a Miraflores se quedaba corto. Añade además una figura nueva como parte del Congreso a los que llama "asistentes a Cortes». Éstos serían nombrados por el Gobierno en cada legislatura, en una proporción que no exceda de 1 por cada 25 Diputados. Tales asistentes tendrían voz, pero no voto.

En cada capital de provincia habría una Comisión de insaculaciones presidida por el Gobernador. Para ser insaculado se requería ser español, de 30 años, con 4.000 reales de contribución o 1.500 reales si procedía de contribución por inmuebles o territorial. Los que habiendo solicitado ser insaculados, aportando una prolija documentación, no fueran admitidos, podrian recurrir a la Audiencia. El nombre de los insaculados se metería en un arca con cuatro llaves, lista para el sorteo cuando se convocara a Cortes.

El ceremonial que propone para el traslado procesional del arca y para su utilización, así como la participación en ello de las autoridades civiles, militares y eclesiásticas, amén de un párvulo menor de 8 años para extraer las bolas resulta casi gracioso, por no llamarlo ridículo. Nos evoca el "arca de la alianza", con todos los respetos, y las prescripciones ceremoniales de la Instrucción electoral de 1810.

Sólo como un dato cronológico aportamos el recuerdo de tan burda proposición. ¿O acaso era chanza repetida dos legislaturas por el Marqués? 


\section{Proyecto electoral de la Unión Liberal}

En pleno apogeo de la Unión Liberal, siendo Presidente del Consejo D. Leopoldo O'Donnell, Conde de Lucena, el Ministro de la Gobernación, Sr. Posada Herrera, que se haría famoso por sus manipulaciones electorales, presentó al Congreso el 28 de junio de 1860 un proyecto de Ley electoral. Éste apenas difiere de la vigente Ley de 1846. En la exposición de motivos dirigida al Congreso afirma que no se trata de una Ley nueva, el proyecto que se presenta, sino más bien una reforma para "mejorar conservando". Sin embargo, presenta un proyecto completo, en el que recoge la Ley vigente con las modificaciones propuestas. El argumento para tal proceder es el de que el Gobierno desea que las disposiciones "que conserva intactas, reciban una consagración definitiva y mayor fuerza en los debates legislativos de que volverán a ser objeto".

Afirma Posada que con la reforma se pretende poner límites a la acción del Gobierno y freno a las demasías de los partidos. Teniendo en cuenta el incremento de población, reconociendo un censo civil de 15.334.078 habitantes, se pretende aumentar el número de distritos y $\mathrm{Di}$ putados, y hacer que las secciones tengan también carácter permanente, para evitar arbitrariedades; reconoce que la modificación de los distritos alterará las "influencias legítimas" de los partidos y "sus medios actuales de acción y propaganda". Nosotros añadimos que permitirá recomponer los distritos para la distribución de la clientela política, según convenga mejor al Gobierno.

Se respeta la mayor base electoral, motivada por un aumento de la riqueza, sin cambiar la base censitaria establecida, pues, según Herrera, reducirla llevaría casi al sufragio universal, «incompatible con nuestras instituciones", y elevarla, para restringir la base, podria hacernos caer en una oligarquía "tan contraria a la corriente liberal de los tiempos" (vid. Exposición de motivos del proyecto de Ley).

El número de distritos pasa a ser de 349 a 389 y el mismo número de Diputados. Aunque aumentan, teniendo en cuenta el aumento de población, pero la proporción disminuye de 1 por 35.000 a 1 por 40.000 habitantes. El sistema en conjunto no varía, salvo en lo referente a las secciones. Éstas, para ser modificadas, requieren determinadas cautelas y un Real Decreto.

No sufre modificaciones lo referente a la condición de elector, candidato o la forma de realizar las elecciones. El número mínimo de electores se duplica, pasando a ser de 300 por cada distrito electoral. En defec- 
to de número suficiente de contribuyentes del nivel requerido por la Ley, se admitiría a los domiciliados más pudientes.

Se mantienen las incapacidades y las incompatibilidades, si bien Herrera se inclina teóricamente por unas incapacidades relativas, frente a otras que pudieran ser absolutas. Los empleados públicos, civiles y militares, sólo pueden compatibilizar la condición de Diputado en Madrid siempre que tengan 30.000 reales de sueldo, y en el caso de los militares, que tengan como mínimo el grado de coronel. También tendrán incompatibilidad aquellos Alcaldes que en su jurisdicción tengan a más de $1 / 3$ de los electores del distrito.

Las listas electorales seguirán confeccionándose por el Gobernador, según el procedimiento ya conocido, pero los incluidos podrán obtener certificación de aquél, que les pueda servir para resolver las dudas que se planteen durante las elecciones. También se imputa responsabilidad al Gobernador por omitir algún expediente.

La composición de la mesa sigue sin ofrecer las garantías necesarias, siguiendo el patrón de la Ley vigente. En cuanto a las papeletas, se permite ahora traerlas preparadas, además de poderlas escribir en el acto, por si o valiéndose de otra persona. A nuestro juicio, traer la papeleta preparada extremaría la posibilidad de coacción, pues el elector podría estar vigilado hasta que depositase la papeleta que se le hubiese impuesto, quedando el hecho más disimulado al no haberse preparado la papeleta en el mismo local.

El escrutinio propuesto ofrece más garantías que el vigente en cuanto el derecho de todo elector presente de comprobar alguna papeleta de votación de la que pueda dudar se hayan leido correctamente los datos de la misma, al atribuir responsabilidad penal al Presidente que no acceda a lo solicitado. Recordemos que también en el proyecto de Bravo Murillo se exigia tal responsabilidad.

Resulta positiva la prohibición de nombrar o cesar Alcaldes durante el período electoral, o suspender Ayuntamientos o Concejales.

El Congreso no llegó a dictaminar el proyecto $y$, en la legislatura siguiente, el Diputado PÉREZ ZAMORA lo volvió a presentar, sin que tampoco se llegara a dictaminar. 
Nuevo proyecto moderado

Desgastado el Gobierno de la Unión Liberal (la izquierda moderada con la derecha progresista) y enemistados algunos de sus Ministros con la Reina (Marqués de la Vega de Armijo y Augusto Ulloa) y la pretensión de O'Donnell de disolver unas Cortes que le iban resultando hostiles, llevaron a la caída de aquél. El nuevo Gobierno debía contemporizar con progresistas y moderados, para propiciar la recomposición de ambos partidos. Y el 2 de marzo de 1863 se encarga de formar Gobierno el Marqués de Miraflores, que duró en el poder diez meses.

Durante tan breve mandato, el Ministro de la Gobernación, Florencio Rodríguez Vaamonde, presenta el 9 de enero de 1864 un proyecto de Ley electoral, firmado el 9 de diciembre de 1863. Siete días después cesaba el Gobierno. Es de señalar que, durante este Gobierno, el 12 de agosto de 1863 se disolvieron las Cortes, que, por una vez, habían alcanzado a completar su mandato ordinario de cinco años.

El proyecto presentado por el Gobierno de Miraflores pretende un eclecticismo conciliador entre la Ley de 1837, la vigente Ley de 1846 y, aun, aprovechar los proyectos anteriores, particularmente el de 1856, del período constituyente fallido, y el del Gobierno predecesor, es decir, el de Posada (vid. Diario de Sesiones de 9 de enero de 1864).

En la exposición de motivos se justifica la necesidad de la reforma por una parte, como Posada, para adecuar la proporcionalidad del número de Diputados con la población real, que es mayor que la que refleja el reparto de la Ley vigente; también que al considerar que la Ley de 1837 falseaba los resultados y la de 1846 favorece las reyertas y parcialidades locales, con menoscabo del interés general, resultaría conveniente unos distritos más amplios que los actuales, y en el supuesto de provincias de poca población coincidirian con ellas. Así se superaría la influencia localista y,sesesalvaría la independencia del Diputado elegido, evitando las circunscripciones provinciales de gran población y sus dificultades inherentes.

La proporción de Diputados sería de 1 por cada 40.000 habitantes o más de la mitad, para que el número de Diputados no crezca excesivamente respecto al actual. Teniendo en cuenta la proporción indicada, cada distrito comprendería el equivalente de población con derecho a elegir entre 3 y 6 Diputados. Las poblaciones de 40.000 habitantes o más formarian distrito propio, así como las provincias con menos de 120.000 habitantes o si tenian menos de 240.000 sin poblaciones de 40.000 habitantes, es decir, que las provincias de $\mathbf{2 4 0 . 0 0 0}$ habitantes con pueblos de 
40.000 habitantes tendrían que respetar el distrito de tales poblaciones, aun en el supuesto de que no les correspondiesen a éstas, 3 Diputados. En estos supuestos, se argumentaba que la población grande o una provincia aún pequeña reunían las condiciones suficientes para que no imperasen los localismos.

Las secciones se compondrían de 200 a 800 electores. La división inicial de distritos la hace el Gobierno y las rectificaciones se hacen por Ley, y respecto a las secciones, por el Gobierno, oído el Consejo de Estado en pleno.

Corresponde al Alcalde señalar el local de elecciones, pero cabe una reclamación constructiva ante el Gobernador, indicando la existencia de locales más adecuados (art. 14).

Las condiciones para ser elector no varian, salvo la de ser seglar, que se omite, atribuyendo tal calidad a los 500 mayores contribuyentes del distrito, por cada Diputado a elegir, incluyendo los que paguen la misma contribución que el menor gran contribuyente admitido (recordemos que en la Ley de 1846 se limita a 150 electores por cada Diputado). Se considera tanto la contribución territorial como la industrial. En caso necesario para completar el número de electores, se aplicaría el ya conocido principio de "más pudientes», estableciéndose el orden riqueza a juicio del alcalde, al menos respecto a los 12 primeros. Esto último tiene relevancia a la hora de constituir la mesa electoral, como más tarde veremos.

Las listas, como en la Ley vigente, deben ser permanentes y de rectificación bienal. Corresponde al Gobernador hacer las mismas, pero en su confección debe atenerse a la documentación remitida por los distintos órganos competentes. Así, la oficina de Hacienda envía las listas de los mayores contribuyentes, los secretarios de las Reales Academias relación de su miembros, etc., y los Alcaldes, sobre la lista provisional que se les envía, hacen constar la edad, nacionalidad, domicilio e impedimentos de que tuvieren noticia. Los excluidos pueden recurrir ante la Audiencia, la cual procede de oficio. Finalmente, todos los que resultan electores reciben un título acreditativo, a semejanza del proyecto de Ley de 1856.

Se amplían las llamadas capacidades (por su título o cargo) admitidas como electores, sin pedirles prueba de contribución o renta, excepto a jubilados que deben acreditar un sueldo no menor a 8.000 reales. Las incompatibilidades se amplían, afectando a los empleados públicos en activo, además de las motivadas por situaciones personales por estar procesados, inhabilitados, concursados, quebrados, embargados y los deudores de fondos públicos. 
El derecho pasivo de sufragio tiene las mismas condiciones ya establecidas. Se hace incompatible la condición de Diputado con empleo civil o militar retribuido, exceptuados los residentes en Madrid, por ser de opinión común de que en tal caso no perjudica la compatibilización. Pero éstos deben disponer de 40.000 reales de sueldo, o la mitad si se trata de Catedráticos o Profesores numerarios de Universidad o de Escuelas especiales. A los militares se les exige el grado mínimo de Coronel. Finalmente, quedan excluidos los Jueces. A las incapacidades para ser elector se añaden también las referidas a tener contratos o reclamaciones con el Estado. La incapacidad sobrevenida, así como la elección parcial cuando se produzcan vacantes, debe ser declarada por el Congreso (arts. 28 y 30$\rangle$.

Se reconoce el derecho de opción a aquellos que al ser elegidos no tenian incapacidad para ello, cuando sean elegidos por varios distritos, o cuando posteriormente accedan a cargo incompatible. En este último supuesto el Diputado debe someterse a reelección.

La mesa electoral interina la componen los 5 mayores contribuyentes presentes, siendo el primero de ellos Presidente y los demás secretarios. Cuando los indicados no quieren o no pueden, se seguirá el orden de la lista electoral, correspondiendo al Alcalde aplicar esta norma. Después se elegirá la mesa definitiva y a continuación se procederá a la elección de los Diputados que correspondan al distrito.

La votación se realiza en dos días, por secciones, y 5 días después corresponde el escrutinio por distritos en la capital, presididos por el Gobernador. Forman la Junta el Presidente y secretario de la sección del distrito que tenga menos votos, $y$ en su defecto, justo al revés, asistidos por 2 Consejeros y 2 Diputados provinciales. El procedimiento es semejante al del proyecto de 1856. En caso de empate, se convoca segunda elección entre los dos más votados.

Cuando las actas del Gobernador no coincidan con las que lleven consigo al escrutinio general los Presidentes y secretarios de sección, resolverán los Tribunales. Las actas en poder del Gobernador las remite el Alcalde (arts. 79 y 80 ).

Se mantiene la tradición de los proyectos más recientes de dedicar un título a las disposiciones penales por delitos electorales, tanto referido a autoridades como a electores. En ellas se castiga al Gobernador, funcionarios y empleados públicos que incumplan sus obligaciones, así como a los electores que cometan fraudes y violencias, como la de impedir a otro que pueda emitir libremente su voto. A los electores en todo caso se les condena a perder el derecho de voto activo y pasivo para la 
convocatoria correspondiente, y si la infracción consiste en presentarse con armas, sólo se le priva del derecho de voto activo.

Como ya sabemos, siete días después caía el Gobierno y el nuevo Gobierno retiró el proyecto, sin dar ocasión a que la Comisión del Congreso lo dictaminara. Al retirarlo el nuevo Ministro prometió presentar un nuevo proyecto que estuviera en "consonancia con los principios políticos" del nuevo Gobierno (vid. Diario de Sesiones de 28 de enero/1864, pág. 870).

Ministro de la Gobernación Antonio Benavides, con el Gobierno de Arrazola, presentaría un nuevo proyecto de Ley electoral el día 21 del mes siguiente. Éste, si bien admite algunos principios procedentes de su predecesor, en su conjunto es más regresivo, dentro del carácter moderado de ambos Gobiernos. Tampoco tuvo éste mejor fortuna, seguramente por la escasa duración del Gobierno, que, habiendo sido nombrado el 17 de enero, sólo duró hasta el 1. de marzo inmediato, menos de mes y medio.

\section{Proyecto de Ley electoral de Antonio Benavides}

El 22 de febrero presentaba su proyecto de Ley electoral el nuevo Ministro de la Gobernación. Decía inspirarse en la Ley vigente y en el proyecto anterior, incorporando además las Leyes de 1849 sobre elecciones parciales (art. 29), y la referida a incompatibilidades, por ser materia propia de una Ley electoral que se encontraba dispersa (vid. Diario de Sesiones de 22 de enero). Indudablemente, el proyecto mejora la sistemática de la legislación electoral, pero no es menos restrictivo en la base electoral que la Ley vigente, de la cual prácticamente no se aparta en esta cuestión, ni en muchas otras.

Los principios doctrinarios que inspiran el sufragio censitario se invocan expresamente en la exposición de motivos al manifestar como límites del derecho electoral "los de la esfera que comprende a todos aquellos ciudadanos de cuyo voto pueda presumirse que reúne las circunstancias de ser inteligente o ilustrado, independiente e interesado en el bien público. El termómetro más seguro, el indicio menos sujeto a error para suponer en el elector estas circunstancias, se ha reconocido generalmente que es la cuota de contribución que paga cada individuo, pues que, en efecto, a pesar de raras excepciones, lo que la razón y la experiencia demuestran es que el que posee un capital o ejerce una industria, no sólo ha dado pruebas de laboriosidad inteligente, no sólo se ha hecho acreedor al goce de los derechos políticos, sino que evidentemen- 
te tiene mayor deseo del acierto en la elección de sus representantes, como interesado más directamente en el buen gobierno...". Éste era el talante de la época, común a progresistas y moderados, aunque con una pretensión más restrictiva en los segundos.

El proyecto mantiene la proporción entre número de Diputados y población, propuesta por su predecesor ( 1 Diputado por cada 40.000 habitantes); por el contrario, respecto a los distritos defiende el distrito uninominal como en la Ley de 1846. Se afirma que tal distrito no es malo porque sea pequeño, y defiende el mismo con los clásicos argumentos ya utilizados por los moderados. Lo malo en estos distritos es la corrupción y el cohecho, y, afirman, con la nueva Ley se va a evitar.

Corresponderá al Gobierno la división en distritos y en secciones. Éstas serán semejantes a las del anterior proyecto (entre 200 y 800 electores); también se podrá reclamar para que se asigne local de elecciones distinto del que haya ordenado el Alcalde.

Son electores los mismos que establece la Ley vigente y además aquellos empleados que reúnan las condiciones de capacidad y renta que se exigen. Si bien esto se formula en el proyecto negativamente, dentro del cuadro de los que no pueden serlo, dando una impresión equívoca. Para la composición o computación de rentas y contribuciones ubicada en distintos distritos, el interesado puede trasladar su derecho del distrito donde paga a aquel en que esté domiciliado. Pero se exige un expediente con prueba documental dentro de los plazos propios de elaboración o rectificación de listas. El carácter restrictivo de esta medida nos parece indudable, ya que dificulta la sencillez de lo que podria ser una mera prueba documental en el propio distrito (arts. 11 y 12).

En los distritos en que no se paga contribución directa, serán electores los 200 mayores pudientes domiciliados en él, y en distritos que se den ambos supuestos, se incluyen de una parte los que paguen la contribución exigida y en otra los mayores pudientes. Entendemos que se trata de secciones en una situación o en otra, dentro de un distrito. $Y$ aun así vemos complicada la presunta aplicación de este principio, pues el proyecto no señala en qué proporción debería designarse de los unos y de los otros (art. 97). Nuestra interpretación es que los más pudientes serían el número mínimo limitado para completar el número de 200 electores, en analogía con lo que la Ley de 1846 establece respecto a los 150 electores. Sin embargo, esta norma, si hubiera llegado a regir, hubiera creado muchos problemas y además podría conducir a que pueblos enteros quedaran sin electores, cuando en la otra parte del distrito hubiese número suficiente de contribuyentes para completar el número mínimo de electores. Aparte de que, no necesariamente todos los contribuyentes, 
desde el punto de vista censitario, tendrían por qué tener mayor riqueza $e$ independencia que los más pudientes de otros pueblos no sujetos a contribución directa, principios estos propios del sistema y que son invocados en la exposición de motivos.

El derecho a ser candidato no difiere en su regulación respecto a la Ley vigente. En cuanto a las incompatibilidades, sigue la regulación del proyecto anterior. La peculiaridad de este proyecto radica en establecer una restricción más, consistente en la pérdida del derecho del electo, cuando no presenta su acta al Congreso en el plazo de un mes. En tal caso se entiende que renuncia al cargo (art. 26).

Para la confección de listas sigue con el procedimiento de la propuesta del Gobierno anterior, marcándole al Gobernador los órganos a que deba recurrir para que expidan las certificaciones oportunas, según las cuales hacer el censo electoral. Una particularidad de este proyecto es que se establece la obligación de que los Gobernadores se remitan entre sí la información sobre contribuyentes domiciliados en provincia distinta y que puedan ser electores. Las listas electorales terminadas deben llevar todos los datos referentes a la identidad, domicilio y base del derecho de cada uno de los electores incluidos en ellas.

La composición de la mesa, tanto interina como definitiva, no difiere de la establecida en la Ley de 1846, pero hay un modesto avance frente a la arbitrariedad del Alcalde, al exigirle que como Presidente de la mesa, cuando tenga que resolver las dudas de edad para componer la mesa interina, lo hará bajo su responsabilidady "con presencia de las fes de bautismo legalizadas", uniéndose estos documentos al acta de elección (art. 62). A esto quizás se refería el Ministro cuando decía que la mesa estaría presidida por la autoridad, pero que ésta no sería "árbitra y dueña del resultado del escrutinio", sino el "fiel ejecutor de lo que la ley prescribe». En un Gobierno del Marqués de Miraflores no podía faltar alguna solución adicional "por sorteo". Así se procede cuando no han sido elegidos suficientes secretarios escrutadores (art. 67).

Papeleta electoral, actas, escrutinios, etc., siguen la pauta de la Ley vigente. Apreciamos alguna incongruencia respecto a que, estando presidiendo la mesa la autoridad, el Alcalde, se invoque que la autoridad acudirá a requerimiento de la mesa, o cuando "se perturbe gravemente el orden", en cuyo caso podría intervenir. ¿Significa esto que cabría una coacción de la autoridad provincial, con su intervención? (ver arts. 94 y 95).

Se incorpora el ya habitual título de disposiciones penales, que no se aparta de sus precedentes, tanto en las figuras tipificadas como en la invocación al Código Penal. 
Cortes desde 1853 hasta el final del Reinado de Isabel II

\begin{tabular}{|c|c|c|c|c|}
\hline Elección & Apertura & Suspensiones & Clausura & Disolución \\
\hline $04-02-53$ & $\begin{array}{l}01-03-53 \\
19-11-53\end{array}$ & $\begin{array}{l}08-04-53 \\
10-12-53\end{array}$ & $09-04-53$ & \\
\hline $04-10-54$ & $08-11-54$ & Constituyentes & & $02-09-1856$ \\
\hline \multicolumn{5}{|c|}{ 2.ำ periodo de la Constitución de 1845} \\
\hline \multirow[t]{2}{*}{$25-03-57$} & $01-05-57$ & & $16-07-57$ & \\
\hline & $10-01-58$ & $06-05-58$ & $13-05-58$ & $11-09-1858$ \\
\hline \multirow[t]{5}{*}{$31-10-58$} & $01-12-58$ & $03-06-59$ & & \\
\hline & $01-10-59$ & $14-11-59$ & $27-01-60$ & \\
\hline & $25-05-60$ & $06-06-60$ & & \\
\hline & $25-10-60$ & $07-02-63$ & & \\
\hline & $09-04-63$ & $06-05-63$ & & $12-08-1863$ \\
\hline $11-10-63$ & $04-11-63$ & & $23-06-64$ & $22-09-1864$ \\
\hline $22-11-64$ & $22-12-64$ & & $12-07-65$ & $13-10-1865$ \\
\hline $01-12-65$ & $27-12-65$ & $11-07-66$ & $03-10-66$ & $30-11-1866$ \\
\hline \multirow[t]{2}{*}{$10-03-67$} & $30-03-67$ & & $03-12-67$ & \\
\hline & $26-12-67$ & $20-05-68$ & & \\
\hline
\end{tabular}

Obsérvese como denominador común la inestabilidad de los gobiernos, fruto de las intrigas palaciegas $y$ de las presiones de los militares $y$ de los poderosos. $Y$ el recurso desde el poder a convocar nuevas Cortes, disolviendo las precedentes, si no le son afectas, es cosa corriente y frecuente. Sólo consiguen cubrir el mandato de cinco años las Cortes de 1858. Es decir, que un mandato largo, pretendido por los moderados, en la práctica resulta imposible por la debilidad de los Gobiernos y la supeditación de éstos a la "confianza regia".

Ley de 22 de junio de 1864, estableciendo el procedimiento y sanción penal en los delitos electorales

Desde la Ley de 1846, se habian hecho varios intentos de sustituirla o reformarla, sobre los cuales hemos reflexionado $y$ hemos visto que ninguno llegó a cuajar. Como frecuente demanda de los últimos proyectos, sobre todo a partir del proyecto de 1851 , sobre disposiciones penales, era la de tomar medidas de organización y penales para atajar el 
abundante fraude que se cometía en los procesos electorales. Por fin llega a cuajar una Ley penal que se sanciona como complemento de la propia Ley electoral. A esta Ley penal, primera y única en el Derecho electoral español, nos vamos a referir.

Era Ministro de la Gobernación D. Antonio Cánovas del Castillo, con otro Gobierno también moderado, presidido por D. Alejandro Mon. Este Gobierno duró seis meses y medio (del 1 de marzo al 16 de septiembre de 1864). Estaban reunidas las Cortes elegidas en octubre de 1863, durante el Gobierno del Marqués de Miraflores. Y estaban compuestas por moderados, salvo un progresista, el Diputado Sr. Garrido. Esto, recordaremos, fue debido a que en su momento los progresistas se retiraron de la contienda electoral, por considerar que determinadas Circulares del Gobierno atacaban el derecho de reunión. En este contexto de dominio del legislativo de los moderados, se debatió y aprobó la referida Ley penal.

El Ministro Cánovas del Castillo retira del Congreso el proyecto de Ley electoral presentado por Benavides "con objeto de estudiarlo" (vid. Diario de Sesiones de 2 de marzo/64). Y posteriormente, el 7 de marzo, obtenido el correspondiente Decreto de la Reina, lo retira definitivamente de la consideración de las Cortes $y$, al mismo tiempo, presenta por otro Decreto un proyecto de Ley de procedimiento y sanción penal de los delitos electorales. El mismo que pasó a ser Ley el 22 de junio siguiente. Esta Ley estuvo vigente hasta la Revolución de 1868, tuvo vigencia provisional en 1877 y, prácticamente, fue incorporada en su contenido, en el capitulo de disposiciones penales de lo que sería la Ley electoral de 1878.

La Ley penal aprobada refleja en su tipificación toda la gama de tropelías fraudulentas de la época.

Entre sus figuras delictivas están las falsedades en documento público cometidas por funcionario, dando o quitando el derecho electoral, castigándolo con prisión menor y multa. También las consabidas inclusiones o exclusiones indebidas; obligar o impedir votar; que el Presidente de la mesa forme maliciosamente la mesa interina, o impida comprobar el contenido del voto, altere las horas de votación de mala fe para despistar a los contrarios, promueva maliciosamente expedientes gubernativos de deudas para incapacitar a alguien; la autoridad que obliga a recomendar electores o a comparecer ante sí; abstenerse de proclamar al electo; el Gobernador que suspenda a autoridades en período electoral; la no remisión íntegra de los expedientes de reclamaciones; doble votación; coartar, influir por dádivas, etc. etc. (vid. arts 6 al 13 de la Ley, en Leyes electorales y proyectos de Ley, Congreso de los Diputados, Madrid, 1906, págs. 196 y ss.). 
A efectos de esta Ley, se consideran funcionarios cualquiera que desempeñe un cargo público, aunque sea temporal y gratuito, aparte de los que lo sean por Real nombramiento.

Se establece la acción popular respecto a los delitos establecidos en esta Ley, con dos meses de plazo para ejercitarla, a contar desde que el acta correspondiente haya sido aprobada o rechazada por el Congreso. Si se procediera a instancia de parte, para admitirse la querella se exige una fianza por posible calumnia o en garantía de que no se desistirá de tal acción hasta que recaiga sentencia que cause ejecutoria (art. 2).

Se atribuye la competencia a los Tribunales, jerarquizada según la persona contra quien se emprenda la acción, procediendo sin distinción de fuero. Es competencia del Tribunal Supremo de Justicia en las acusaciones contra los Gobernadores y otras personas de igual o superior rango. Corresponde a las Audiencias cuando se procede contra los Consejeros provinciales, Alcaldes y demás empleados públicos. $Y$ a los Juzgados cuando se promuevan las acusaciones contra cualquiera otra persona.

Ley electoral de 18 de julio de 1865

El Consejo ministerial de Mon, de duración tan escasa, como ya hemos señalado, fue sustituido por el de otro moderado, Ramón Narváez, con poco más de diez meses en el poder. Durante el mismo no hay aportación alguna al derecho electoral; más bien, su Gobierno es de triste recuerdo por la famosa cuestión de "el Rasgo" y la sangrienta noche de San Daniel ( 10 de abril de 1865). Estos sucesos, junto a la creciente hostilidad de los progresistas, incluidas las acciones revolucionarias del general Prim, movieron a la Reina encargar nuevo Gobierno a D. Leopoldo O'Donnell (21-6-65). Éste intentó apaciguar los ánimos de los progresistas tratando de incorporarles al poder, sin conseguirlo. Ante lo cual procuró practicar una política liberal que pudiera contentarles. El 13 de octubre disolvió las Cortes del año anterior y convocó nuevas elecciones para el 1. de diciembre. Previamente presentó un proyecto de Ley electoral, que rebajaba a 200 reales la exigencia censitaria para ser elector.

Este proyecto llegó a ser Ley, sustituyendo a la Ley de 1846, y pese a su pretendida transitoriedad, manifestada al ser leida en el Congreso, estuvo vigente hasta la revolución de 1868, que destronó a Isabel II. 
El proyecto fue elaborado precipitadamente, y el propio proceso legislativo para aprobarlo suscitó las protestas de muchos Diputados, ya que lo que se sometía al Congreso era en realidad una delegación legislativa a favor del Gobierno, revestida de la fórmula de "Ley autorizando al Gobierno el planteamiento de la Ley electoral para Diputados a Cortes" (vid. Diario de Sesiones de 22 de junio/1865).

La vía legislativa utilizada nos recuerda la pretensión de Bravo Murillo de que se aprobaran en bloque los nueve proyectos publicados en la Gaceta de Madrid, sin que fueran discutidos (vid. la referencia en este mismo trabajo). Pero esta vez se conseguiría la pretensión y se sentaría el precedente, que se repetiria con la Ley electoral de 1878. Aunque en esta ocasión su contenido había sido pactado previamente.

La Comisión del Congreso se limitó en su trabajo a hacer correcciones de estilo y de sistemática, en un apresurado proceso de cuatro días, desde el 26 de junio en que se constituye la misma al 30 del mismo mes (vid. Diario de Sesiones del 26 y del 30 de junio de 1865).

El argumento para tanta precipitación es la necesidad de disponer de una Ley electoral con nuevas bases para las inminentes elecciones que se piensan convocar. Aparte de que la proximidad de las vacaciones de verano podrían dificultar la terminación de la Ley, si tuviera que discutirse de acuerdo con el proceso legislativo normal (vid. Exposición de motivos en el propio proyecto de Ley). En el debate se echa de ver el interés de contentar a los progresistas (vid. THOUS y otros, en Diario de Sesiones de 30 de junio, pág. 732 y ss.). También parece que al Gobierno le urge deshacerse de unas Cortes que no le son realmente favorables (vid. Diario de Sesiones de 5 de julio, CAPUA, pág. 3035). Después de tantos intentos de reforma de la Ley de 1846, nos parece de difícil justificación el apresuramiento para elaborar una Ley política de tal relevancia, máxime cuando tanto el Gobierno como la Comisión del Congreso reconocen su improvisación y consiguiente imperfección (ibid., pág. 3031). BREMON atribuye los antecedentes de esta Ley a una proposición de Ley de Hurtado y otros (vid. Diario de Sesiones del Congreso de 26 de mayo y el de 26 de junio, pág. 3004).

Era Ministro de la Gobernación JOSÉ DE POSADA HERRERA, como ya lo fue con la anterior etapa de Gobierno de la Unión Liberal. Al defender el proyecto, expresó en protestas de sinceridad y buena voluntad para que en el futuro las elecciones se celebren sin fraudes, defendiéndose por su mala fama, "ciertamente inmerecida». Esto provocó las risas de la Cámara y le contestó a su vez APARISI Y GUIJARRO con su probada elocuencia, llamándole "pecador antiguo y converso de ayen, al que habría que poner a prueba. Replicó con no menos destreza Posada, de- 
fendiéndose de sus ataques y haciendo protestas de su sincero deseo de establecer una base legal que impida los aabusos del pasado (vid. Diario de Sesiones de 4 de julio, pág. 2998 y ss.).

Sometido a votación el proyecto, fue aprobado por 171 votos a favor y 27 en contra.

Según el Gobierno, la división en distritos había sido perturbadora y suscitado rencores entre los pueblos. La Ley de incompatibilidades no remedió la situación, ni aun la reciente Ley penal. Por otra parte, la elección por distritos provinciales ofrecía el inconveniente de que las grandes poblaciones absorbían la vida politica rural. Para evitar ambos inconvenientes establecen en esta Ley grandes distritos electorales. Estos distritos tendrán hasta 7 Diputados, según su población, y las ciudades de $\mathbf{4 5 . 0 0 0}$ habitantes formarán distrito aparte. La proporción de Diputados será de uno por cada $\mathbf{4 5 . 0 0 0}$ habitantes o fracción de más de la mitad. La división en secciones, para facilitar el ejercicio del voto, se corresponderá con la de partidos judiciales, procediéndose por la misma Ley a hacer las divisiones correspondientes, que sólo podrán ser modificadas mediante ley.

Para ser elector se reduce la cuota de contribución exigida a 20 escudos, 200 reales, la misma que en la Ley de 1837, satisfecha desde un año antes, si es contribución territorial, o de dos años si se trata del subsidio industrial. A los colonos y aparceros se les reconoce un tercio de la contribución de las tierras que cultivan, para integrar la composición necesaria para ser elector, reservando los $2 / 3$ para el propietario. Respecto a las llamadas capacidades, se reduce la exigencia, ampliando el derecho correspondiente a los coadjutores, capitanes y hasta a maestros de primera enseñanza con título y un año de ejercicio.

Para Vascongadas y Navarra, al no pagarse contribuciones directas, se establece un régimen especial consistente en acreditar propiedades o capital industrial o mercantil equivalentes a una renta de 150 escudos. Esta cifra nos resulta extraña, pues 150 escudos equivalen a 1.500 reales, pero no hemos podido contrastar la posible errata. Creemos que debe referirse a 15 escudos (150 reales).

Queda en la ambigüedad la exigencia para ser candidato, pues la Ley se limita a exigir que satisfaga contribución directa al Estado, sin concretar cuantía. Obviamente, la misma no podría ser inferior a la exigida para ser elector. No nos consta. Las incapacidades y limitaciones no ofrecen grandes novedades respecto a lo que venimos contemplando. No pueden ser elegidos los que hubieren jurado cargo de Diputado, si no renunciaron expresamente a él antes de la nueva elección; los inhabilita- 
dos; los condenados a penas aflictivas y no rehabilitados; los procesados criminalmente, con auto de prisión; concursados o quebrados, no rehabilitados; deudores a fondos públicos; contratistas de obras o servicios públicos, y los que tengan pendientes reclamaciones por contratas con el Gobierno, así como sus fiadores y mancomunados. Además tienen incompatibilidad los empleados de Real nombramiento en sus provincias respectivas; los funcionarios de otra procedencia que ejerzan autoridad civil o militar; los Diputados provinciales, y los contratistas de obras o servicios provinciales. La incompatibilidad sobrevenida debe ser declarada por el Congreso cuando se produzca.

Para la realización de las listas electorales se establece un procedimiento especial a cargo del Gobernador, con recurso ante la Audiencia respectiva (Título $X$ de la Ley). Las inclusiones o exclusiones futuras serán competencia del Juez de primera instancia de los partidos judiciales comprendidos en el distrito o sección. Corresponderá para ello la acción popular a cargo de los ya inscritos o del interesado en ello, sin límite de tiempo para iniciarla. Se incluyen una serie de garantías, como la de ser oído el Ministerio Fiscal, la documentación probatoria de las condiciones de edad, vecindad y renta, así como la publicidad por edictos y en el Boletín oficial de la provincia (vid. Leyes..., arts. 25-39). Los términos son muy breves y las sentencias apelables ante la Audiencia en el término de tres días. Junto a esta regulación procesal, la Ley reconoce como supletorias las reglas generales de sustanciación de la Ley de Enjuiciamiento Civil. El procedimiento es de oficio. En suma, el procedimiento viene a ser como el propuesto en el proyecto de 1863, adicionando a las listas vigentes las complementarias que resulten de la extensión del voto $y$ de las correcciones por cambios de situación (vid. arts. 103 y ss.). En definitiva, son los órganos gubernativos los que hacen las listas, si bien con garantías de carácter judicial.

La rectificación de las listas es anual, realizadas por los Secretarios de los Ayuntamientos cabeza de sección, que llevan un libro "Registro del censo electorals. Además, actuará una Comisión permanente de inspección, compuesta por el Alcalde y 4 Concejales, que es responsable conjuntamente con el Secretario. Esta rectificación en realidad no atribuye el derecho de voto, sino que corrige el "censo", teniendo en cuenta las aportaciones documentales del Registro civil (fallecimientos) y de las decisiones judiciales sobre exclusiones, inclusiones, inhabilitaciones, etc. Los interesados podrán reclamar a la Comisión y después al Gobernador, en queja. Por comunicación de los interesados, el cambio de domicilio dentro de la sección lo hace la propia Secretaría municipal, pero la Ley no prevé el supuesto de cambio de domicilio fuera de la sección o del distrito. Ante esta laguna, entendemos era necesario recurrir al expediente judicial, para que el elector recupere su derecho. 
En el Registro del censo se incluye una relación ordenada de contribuyentes por orden de cuota que satisfacen; esto facilitaba la mecánica de constitución de la mesa electoral.

Los locales para las elecciones son señalados por el Gobernador para evitar abusos de las autoridades locales, y el Presidente de la mesa será el primer contribuyente de entre los cinco primeros contribuyentes de la sección, y en su defecto por el Alcalde. En los supuestos de empate decide la edad, probada documentalmente.

Determinado el día precedente, teniendo en cuenta el Libro del censo, quién es el Presidente de la mesa (uno de los 5 primeros contribuyentes o el Alcalde), se compone la mesa interina, presidida por quien corresponda, y cuatro secretarios escrutadores que serán los dos electores más viejos y los dos más jovenes de los presentes en el local de elecciones. Las dudas se resolverian mediante documentación, para evitar pretextos que permitan apoderarse de la mesa interina a quien no corresponda. A continuación se procede a elegir a los 4 secretarios de la mesa definitiva. El sistema ya es conocido, se eligen entre los presentes, entregando cada uno una papeleta con dos nombres. $Y$ a falta de alguno, los elegidos con el Presidente eligen a los que falten (art. 68). Esta forma de coopción, ya pretendida en varios proyectos anteriores, resulta totalmente innecesaria, ya que la pretensión de que no acapare la mesa un solo grupo queda desvirtuada. Para esto hubiera sido preferible que directamente pusieran cuatro nombres en la papeleta.

Constituida la mesa, las elecciones de sección duran tres dias. La papeleta de votación debe llevar tantos nombres como Diputados a elegir en el distrito correspondiente. Puede traerse preparada, o prepararla en el propio local, por sí o valiéndose de otra persona. Si excediera el número de nombres, sólo son válidos los primeros hasta completar el número requerido, anulándose el resto.

Los resultados parciales de las votaciones de sección, correspondientes a cada día, así como el resumen final, se formulan en el acta correspondiente y se les da publicidad, conservándose las papeletas discutidas para ser enviadas al Congreso junto con el expediente (art. 76). Los candidatos pueden obtener certificación de los resultados que se vayan produciendo, con lo cual se pretende una nueva garantía de los resultados electorales.

Quizás lo más original de esta Ley sea que establece una Junta electoral de distrito, presidida por el Juez de primera instancia más antiguo, con voz y voto. Esta cuestión suscitó gran debate al discutirse el proyecto de Ley en el Congreso. El Diputado Manresa propuso como caute- 
la que se adicionase en la Ley la inamovilidad de los Jueces, pero fue rechazada su propuesta, considerada innecesaria por estar establecida ésta en la propia Constitución (art. 69). Algunos oponentes pusieron de manifiesto que era contrario a la Constitución hacer que los Jueces presidan la Junta electoral, por cuanto el art. 66 de la Constitución les atribuía la "potestad de aplicar las leyes... sin que puedan ejercer otras funciones que las de juzgar y hacer que se ejecute lo juzgado". Tampoco fueron tenidos en cuenta.

Como los electos son proclamados por mayoria absoluta, si faltan más de un tercio de los que hay que elegir, se realiza una segunda elección con los demás, a razón de dos candidatos por cada puesto que quede pendiente de cubrir. En el caso de que no falten en tal proporción, se sobreentiende que podrán ser proclamados electos por mayoría relativa. Nos parece razonable la solución, como medio de no cansar demasiado al electorado.

El artículo 90 de la Ley nos resulta contradictorio, pues dispone que «la Junta no podrá anular ningún acta ni voto" y sin embargo luego admite que la Junta decidirá por mayoría absoluta cuando surja sobre el recuento alguna duda.

Se incorporan a esta Ley las leyes de 1849 sobre elecciones parciales y sobre incapacidades. Por otra parte, la Ley de sanción penal aprobada el año anterior sigue vigente en cuanto no se opone a ésta, sino que la completa, ya que, de acuerdo con la cláusula derogatoria, sólo deroga las disposiciones anteriores que se opongan a la nueva Ley electoral. $Y$ es por ello por lo que la nueva Ley prescinde de disposiciones penales, contrariamente a la anterior y a la mayoría de los proyectos de Ley.

Con esta Ley se cierra el ciclo de la legislación electoral propio de la Constitución de 1845 . Y casi también se agota la aplicación del sufragio censitario, aunque aún hay una somera vuelta durante el Reinado de Alfonso XII. Pero a lo largo de este período se van desmoronando los principios doctrinarios, abriéndose hacia realidades más democráticas.

Normas electorales de las Cortes constituyentes de 1856

Real Decreto de 11 de agosto de 1854

Correspondiendo el bienio 1854-56 a la etapa de suspensión de la vigencia de la Constitución de 1845, y siendo su tarea legislativa de gran 
importancia en materia constitucional y electoral, no podemos dejar de incluir esta mínima referencia al mismo. Su influencia próxima alcanzaria a la futura Ley electoral de 1865 y a la Constitución de 1869.

Entre los dos periodos de vigencia de la Constitución de 1845, ésta es una etapa revolucionaria, apoyada principalmente por los progresistas más exaltados, junto con militares no menos revoltosos. Una serie de sucesos precipitan la acelerada caída de los Gobiernos.

Después de los Gobiernos del Conde de Alcoy, Federico Roncali, que duró cuatro meses (14-12-52 a 14-4-53), y el de Francisco Lersundi, con 5 meses de duración (14-3-53 a 19-9-53), ambos moderados, siguió el del Conde de San Luis, Luis J. Sartorius, con nueve meses de gobierno (19-9-53 a 17-7-54). Este último procedió con tal dureza y falta de discreción que se enfrentó a las Cámaras, suspendiendo sus sesiones el 10 de diciembre de 1853, y relevó de lista y nómina a generales como O'Donnell y Concha, desterró a otros, dejó cesantes a varios altos cargos, prendió a otros, sujetó con amenazas a otros, cerró el Ateneo, siguió con la política de influencias en la conexión de ferrocarriles o en la contrata de importantes obras, como la del puerto de Barcelona. Tanta opresión e inmoralidad dejó al Gobierno enfrentado con la opinión pública, desatándose la pasión de los partidos, que hablaban ya de sustituir incluso la dinastía.

Comenzaron las intentonas de alzamiento, sin mucho éxito pero con crecientes posibilidades de triunfar. Las cosas de mal en peor obligan al Gobierno a dimitir, al tiempo que proponía a la Reina como nuevo Presidente del Consejo a Fernando Fernández de Córdoba, como así hizo ésta (17-7-54). Pero debido a la oposición de los progresistas a que les presidiera el indicado, éste dimitió un día después, aunque quedó como Ministro de la Guerra, tomando posesión de la Presidencia el Duque de Rivas, Ángel Saavedra, que a su vez dimitió al día siguiente (18-7-54 a 197-54, y como interino hasta el día siguiente). El 20 de julio de 1854 era relevado por el General Espartero, que había sido llamado para salvar la situación tan grave en que se encontraba el país. Éste requirió a O'Donnell para que formara gobierno con él, $y$, aparte de otras medidas, convocó elecciones a Cortes constituyentes por Real Decreto de 11 de agosto /vid. SÁNCHEZ AGESTA, Historia del Constitucionalismo español, pág. 273 y ss.; SANTAMARÍA DE PAREDES, Curso de Derecho Político, pág. 653; SEVILLA ANDRÉS, Historia Constitucional de España, págs. 123-125).

Se convocan Cortes Constituyentes por Real Decreto de 11 de agosto de 1854, como ya ha quedado dicho. La exposición de motivos dirigida a la Reina fue suscrita por todo el Consejo de Ministros. En ella se argumenta que uen los azarosos días que precedieron al completo triunfo del glorioso alzamiento nacional los pueblos aclamaron la convoca- 
ción de Cortes Constituyentes como el mejor y único remedio en la angustiosa situación a que se los había reducido..." (vid. Leyes, pág. 203). Se pretende celebrar tales Cortes con una sola Cámara, el Congreso, conforme con la tradición constituyente de 1812 y 1837, evitando conflictos con el Senado, que tiene distintos intereses, sin prejuzgar un futuro unicameral o bicameral.

Se rechaza la aplicación de la Ley electoral de 1846, por considerarla de resultados funestos, y no queriendo improvisar, se acogen a la Ley de 20 de julio de 1837, que permite una mayor extensión del sufragio y la consideran más adecuada a los intereses generales. Pero ésta queda modificada en varios aspectos, en virtud del propio Real Decreto. Por una parte, recogiendo dos aspectos de la Ley de 1846, referidos a cómo formar las mesas electorales y a la proporcionalidad del número de Diputados, que será de 1 por cada 35.000 habitantes. Así el número de Diputados será mayor, lo cual consideran del mayor interés, por cuanto estas Cortes serán unicamerales. También suprimen la elección de Diputado suplente.

Para la elección de la mesa se pone en la papeleta el nombre del elegido como presidente y dos para secretarios, quedando elegidos Presidente el de más votos $y$, a su vez, 4 secretarios los que hayan obtenido más votos para tal cargo. La votación se reduce a 3 días, en vez de los 5 días del art. 28 de la Ley de 1837. Se reconoce el derecho que tiene todo elector a comprobar las papeletas, tanto para la elección de mesa como las referidas a la elección de Diputados.

Se extienden tres copias del acta de la elección. Una para el comisionado que vaya al escrutinio general, otra para el Gobernador de la provincia y otra para el Ministro de la Gobernación, que debe pasarla a la Secretaría de las Cortes, para que éstas, cuando se reúnan a través de la Comisión de actas, vean las diferencias que encontraren respecto a las que presenten los diputados electos, y lo sometan al Congreso para que tome los acuerdos que considere justos.

Se celebraron las elecciones el 4 de octubre y se abrieron solemnemente sus sesiones el 8 de noviembre de 1854. Dichas Cortes elaboraron una Constitución y se presentó a las mismas un proyecto de Ley electoral. A ellos no referiremos a continuación.

\section{Normas electorales de la Constitución de 1856}

El 9 de julio de 1855 se presentaba en las Cortes un proyecto de Constitución, que había sido redactado por una Comisión encargada por las mismas Cortes, ajustándose a unas Bases que habian sido aprobadas 
previamente. Pasadas las vacaciones estivales, a partir del 1. de octubre las Cortes volvieron a reunirse para discutir el proyecto de Constitución. Terminaron y aprobaron su tarea en enero de 1856, pero esta Constitución no llegó a ser promulgada. La misma es un antecedente de lo que sería la Constitución de 1869. Dedica la misma el Título II a la composición del Senado y el Título siguiente referido al Congreso.

Al Senado se le restituye la tradición de 1837 de que los Senadores sean elegidos y en un número igual a tres quintas partes de Diputados, pero ya no los nombra el Rey. Son elegidos del mismo modo que los Diputados. Se renuevan al tiempo que el Congreso por cuartas partes, según un orden de antigüedad. Coincide con la Ley electoral de 1837, la exigencia de 3.000 reales de contribución o 30.000 reales de sueldo, si bien ahora también se admite a aquellos que tengan esta última cantidad en concepto de rentas o de jubilación, sin que se acepte composición entre los distintos conceptos. También la edad requerida sigue siendo 40 años.

En cuanto a los Diputados, aparte de requerir ser español y seglar, se remite a las demás circunstancias que exija la Ley electoral. El mandato vuelve a ser de tres años y los distritos provinciales. La proporción entre número de Diputados y población sigue siendo de 1 Diputado como mínimo por cada 50.000 habitantes. Igual que en 1837 .

Es importante señalar que en esta Constitución se regula en el Título XV el procedimiento de reforma de la misma (arts. 87 al 91) y en el mismo Título da rango de Ley fundamental a varias leyes políticas, entre ellas a la Ley electoral, con el fin de darles mayor estabilidad. Al considerarse tales leyes parte de la Constitución, se exige el mismo procedimiento especial para su reforma (art. 92). Recordemos que salvo en la Constitución de Cádiz (art. 375 y ss.), en las Constituciones precedentes no se contemplaba ningún procedimiento especial de reforma constitucional. Además, los constituyentes de esta Constitución previeron un control de constitucionalidad (art. 372), cuestión que es ignorada en la «non nata» Constitución de 1856.

\section{Proyecto de Ley electoral de Patricio de la Escosura}

Aprobada la Constitución, se aborda la elaboración de la Ley electoral, de indudable relevancia política. El 8 de mayo de 1856, el Ministro de la Gobernación, Patricio de la Escosura, presentó el correspondiente proyecto, firmado el día anterior. Tiene el mismo, importantes innovaciones que servirán de antecedente para la legislación futura, incluso respecto a la Ley electoral de 1865, con un Gobierno de la Unión Liberal. EI 
derecho de reunión y de propaganda electoral, así como la pretensión de una policia independiente de la autoridad politica, son instituciones destacadas de este proyecto.

Según el proyecto Escosura, para ser elector se requieren las condiciones comunes ya conocidas (nacionalidad, edad y domicilio), y además que reúna alguna de las siguientes condiciones:

- Satisfacer un mínimo de 120 reales de contribución en cualquier parte del país y por cualquier concepto, o renta equivalente.

- Ser jubilado civil con 40.000 reales de jubilación.

- Haber sido Senador o Diputado.

Se incluyen un gran número de "capacidades", incluido ser canónigo o párroco.

Finalmente, los mayores contribuyentes necesarios para completar un número mínimo de 500 electores por cada Diputado a elegir. $Y$ como ya conocemos, se les agrega todos aquellos que paguen igual contribución que el último designado, o, en provincias que no se pague contribución, aquellos que tengan igual renta.

Con estas condiciones se amplía el censo en gran medida y se supedita menos a las discriminaciones locales el que alguien pudiera ser admitido como elector. Claramente esto favorecería a los progresistas.

Cada elector, aparte de estar incluido en el censo electoral para poder ejercer su derecho, debía tener un título que se le extendería para acreditar su derecho y serviría en cada elección, para poner al dorso diligencia de haberlo ejercitado. Así se evitaría el fraude muy corriente de votar más de una vez.

Correspondería hacer las listas a una Comisión del Ayuntamiento y aprobadas por el mismo. A continuación se procederia a las rectificaciones, remitiéndose después a la Diputación provincial, que podría hacer una ulterior rectificación a la vista del expediente. Se reserva al Gobernador resolver las diferencias o los casos que considerase anómalos, quedando finalmente expedita la vía contencioso-administrativa. Las listas electorales son permanentes, públicas, de rectificación bienal, salvo supuestos de cambio de domicilio, defunción, inhabilitación y los de adquisición o recuperación del derecho electoral. Los interesados tienen acceso al expediente. Queda prohibida toda rectificación en periodo electoral, a partir de la convocatoria de elecciones. 
Para ser candidato se exige, además de las condiciones ordinarias, ser seglar, estableciéndose además unos supuestos de incompatibilidad referidos a altos cargos. Exigiéndose la reelección si el Diputado fuera elegido para un alto cargo. También se reconoce el derecho de opción entre dos cargos, caducando el mismo vencido el término, a favor del cargo que ya detenta. A los Senadores se les exige 40 años de edad, en lugar de 25 años, no son necesariamente seglares y deben tener una renta o sueldo de 30.000 reales, o pagar una contribución de 3.000 . El derecho sigue siendo voluntario, renunciable y gratuito.

El distrito electoral vuelve a ser la provincia, como en 1837. Y ésta se divide en colegios electorales para facilitar el ejercicio del derecho de voto. Cada colegio tendria entre 500 y 1.000 electores. La división correspondería a la Diputación provincial, y después de ser hecha pública, rectificada por el Gobernador, con exposición de motivos $y$ atendidas las reclamaciones. Finalmente, se remite al Gobierno para que le dé la aprobación definitiva. Los cambios seguirían un proceso semejante, pero quedaban prohibidos a partir de la convocatoria de elecciones, hasta que terminasen las mismas.

Según el estado que se adjuntaba al proyecto de Ley, debían elegirse, por sufragio directo y secreto, 303 Diputados y 185 Senadores. La proporción establecida era de 1 Diputado por cada 40.000 habitantes o fracción de 20.000. Los Senadores, que dejaban de ser de libre designación real, e incluso excluido el sistema de 1837 de elegir una terna para que la Reina eligiera de cada terna, pasan a ser elegidos directamente en la proporción de 3 Senadores por cada 5 Diputados, si bien se tenía en consideración a las provincias pequeñas para que tuvieran al menos uno, si les correspondian uno o dos Diputados, dos Senadores las que les correspondan tres Diputados, y tres las de cuatro.

Preside la mesa electoral provisional el Alcalde, y como secretarios los dos más viejos y los dos más jovenes de los presentes. Las dudas de edad se resuelven por la presentación de la fe de bautismo legalizada, y a falta de ésta decide por unanimidad la totalidad de la Junta de electores presentes.

Para votar hay que presentar el título de elector, del que ya hicimos referencia, y estar en la lista electoral. Los casos dudosos se resuelven por la mesa al final de la elección. Se incorporan al proyecto de Ley normas prácticas para interpretar las papeletas dudosas, las duplicadas y las que falten al secreto por ir firmadas. Deben ponerse en la papeleta tantos nombres como Diputados y Senadores correspondan a elegir en la provincia del elector, pudiendo traerse preparada o escribirla en el acto, por sí o valiéndose de otro. 
Las elecciones duran 4 dias y en cada uno de ellos se envía al Gobernador el acta parcial y al final la general del respectivo colegio. En las actas deben quedar reseñadas todas las cuestiones suscitadas. Ocho días después de terminadas las elecciones corresponde reunirse la Junta general de cada provincia, que debe presidir el Gobernador y con asistencia del Presidente y un secretario de cada colegio, más los Diputados provinciales. Un secretario por colegio, que no sea el propio, junto con algún Diputado provincial, examinarian las actas, y posteriormente, en sesión pública, se debe realizar la discusión final y la aprobación de los resultados.

Producidas vacantes, deben cubrirse las mismas dentro de los 45 días desde que la Cámara las declare.

Las violencias y falsedades quedarian sujetas a responsabilidad ante los Tribunales ordinarios, sin distinción de fuero. La acción podria ejercitarse de oficio o a instancia de la autoridad.

Se reconoce libertad de reunión, sin licencia gubernativa. A partir de que el Gobierno convocara elección y hasta la vispera de la elección se podrían hacer reuniones para discutir y aprobar candidaturas, responsabilizándose del orden de las reuniones, como mínimo, cinco electores de los participantes.

No sería necesario el permiso de la autoridad, como se venía exigiendo en el régimen vigente, sino que bastaría con notificarlo 24 horas antes. La convocatoria Real de elecciones debía hacerse 30 dias antes y la gubernativa con 20 días.

A estas reuniones podria la autoridad enviar un agente del Gobierno, con poder para disolver las reuniones que infligiesen la Ley electoral o faltasen al orden, pero también responsable por sus acciones $u$ omisiones indebidas, es decir, justiciable, hablando en términos de la época.

También se permitiría la propaganda impresa responsable, ajustándose a la Ley de imprenta. En cuanto a los anuncios o carteles, se requeriría la licencia previa de la autoridad, que la negará si la materia es ajena a las elecciones o injuriosa (arts. 46 y ss.).

Otro tema interesante de este proyecto de ley es el de la regulación de la policía de los colegios electorales. A esta cuestión se dedica el Capítulo VIII (arts. 113 a 123). Se trata de poner a disposición del Presidente del colegio electoral una fuerza y autoridad por encima del poder gubernativo, que le estará sometida en cuanto haga referencia a las elecciones. 
En la puerta, un agente impedirá el acceso al local donde se celebran las elecciones a todo el que no presente el título de elector. Aunque no se permite entrar con armas o bastones, e incluso paraguas, podrán entrar los enfermos notorios con muletas y la autoridad y los Jueces que de oficio y requeridos por el Presidente, o en caso de tumulto, accedieren al colegio electoral en cumplimiento de su obligación. También podrán estar armados donde y según disponga el Presidente los agentes puestos a su disposición para salvaguardar el orden. El Presidente podrá negar el uso de la palabra en el local de elecciones, expulsar e incluso reducir a prisión, de acuerdo con la mesa, a quien perturbe la marcha de las elecciones, pero sin impedir el ejercicio del derecho a votar. Los incidentes se reflejarán en acta.

Este proyecto que acabamos de examinar no llegó a dictaminarse por las Cortes debido al cambio de Gobierno. El Gobierno, basado en progresistas y moderados de centro, fue atacado en las Cortes por los más exaltados de ambas tendencias, y además minado por la pugna interna entre O'Donnell, que era Ministro de la Guerra, y Patricio de la Escosura, Ministro de la Gobernación. Termina con la crisis del 14 de julio de 1856. Dimitido Espartero, la Reina encarga a O'Donnell la Presidencia del Consejo de Ministros. Y éste consigue el Real Decreto de disolución y disuelve las Cortes Constituyentes el 2 de septiembre. El bienio habia terminado sin que se consolide el trabajo realizado por las Cortes. 